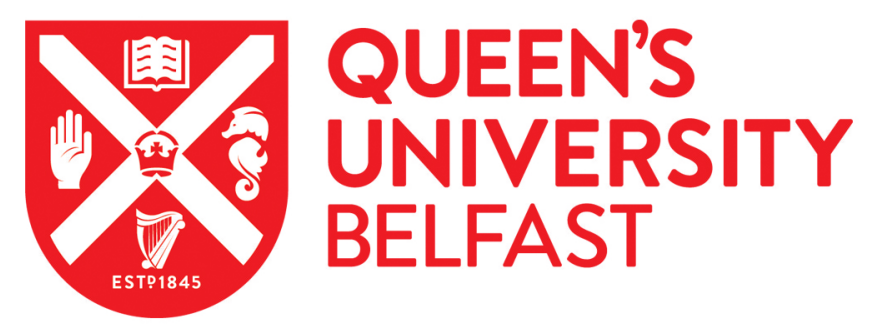

\title{
International trends in oesophageal cancer survival by histological subtype between 1995 and 2014
}

Morgan, E., Soerjomataram, I., Gavin, A. T., Rutherford, M. J., Gatenby, P., Bardot, A., Ferlay, J., Bucher, O., De, P., Engholm, G., Jackson, C., Kozie, S., Little, A., Møller, B., Shack, L., Tervonen, H., Thursfield, V., Vernon, S., Walsh, P. M., ... Arnold, M. (2020). International trends in oesophageal cancer survival by histological subtype between 1995 and 2014. Gut. https://doi.org/10.1136/gutjnl-2020-321089

\section{Published in:}

Gut

\section{Document Version:}

Peer reviewed version

Queen's University Belfast - Research Portal:

Link to publication record in Queen's University Belfast Research Portal

\section{Publisher rights}

Copyright 2020 BMJ. This work is made available online in accordance with the publisher's policies. Please refer to any applicable terms of use of the publisher.

\section{General rights}

Copyright for the publications made accessible via the Queen's University Belfast Research Portal is retained by the author(s) and / or other copyright owners and it is a condition of accessing these publications that users recognise and abide by the legal requirements associated with these rights.

Take down policy

The Research Portal is Queen's institutional repository that provides access to Queen's research output. Every effort has been made to ensure that content in the Research Portal does not infringe any person's rights, or applicable UK laws. If you discover content in the Research Portal that you believe breaches copyright or violates any law, please contact openaccess@qub.ac.uk. 
International Trends in Oesophageal Cancer Survival by Histological Subtype between 1995 and 2014

Eileen Morgan ${ }^{1,2}$, Isabelle Soerjomataram ${ }^{2}$, Anna Gavin ${ }^{1}$, Mark J Rutherford ${ }^{2,3}$, Piers Gatenby ${ }^{4}$, Aude Bardot $^{2}$, Jacques Ferlay ${ }^{2}$, Oliver Bucher ${ }^{5}$, Prithwish De ${ }^{6}$, Gerda Engholm ${ }^{7}$, Christopher Jackson ${ }^{8}$, Serena Kozie $^{9}$, Alana Little ${ }^{10}$, Bjørn Moller ${ }^{11}$, Lorraine Shack ${ }^{12}$, Hanna Tervonen ${ }^{10}$, Vicky Thursfield ${ }^{13}$, Sally Vernon ${ }^{14}$, Paul M Walsh ${ }^{15}$, Ryan R Woods ${ }^{16}$, Christian Finley ${ }^{17}$, Neil Merrett ${ }^{18}$, Dianne L $\mathrm{O}^{\prime}$ Connell ${ }^{19}$, John Reynolds ${ }^{20}$, Freddie Bray ${ }^{2}$, Melina Arnold ${ }^{2}$

${ }^{1}$ Northern Ireland Cancer Registry, Queen's University Belfast, Belfast, Northern Ireland

${ }^{2}$ Section of Cancer Surveillance, International Agency for Research on Cancer, Lyon, France

${ }^{3}$ Department of Health Sciences University of Leicester, Leicester, Leicestershire UK

${ }^{4}$ Department of Clinical and Experimental Medicine, University of Surrey, Guildford, Surrey, UK

${ }^{5}$ Cancercare Manitoba, Department of Epidemiology and Cancer Registry, Winnipeg MB, Canada

${ }^{6}$ Cancer Care Ontario, Surveillance and Cancer Registry, Toronto, Ontario, Canada.

${ }^{7}$ Danish Cancer Society, Copenhagen, Denmark

${ }^{8}$ Cancer Society of New Zealand, Wellington, New Zealand

${ }^{9}$ Saskatchewan Cancer Agency, Regina, SK, Canada

${ }^{10}$ Cancer Institute NSW, Cancer Information and Analysis, Eveleigh NSW, Australia

${ }^{11}$ Cancer Registry of Norway, Institute of Population-based Cancer Research, Oslo, Norway

${ }^{12}$ CancerControl Alberta, Alberta Health Services, Edmonton, AB, Canada

${ }^{13}$ Victorian Cancer Registry, Cancer Council Victoria, Melbourne, Victoria, Australia.

${ }^{14}$ National Cancer Registration and Analysis Service, Public Health England, Cambridge, United Kingdom.

${ }^{15}$ National Cancer Registry Ireland, Cork, Ireland.

${ }^{16}$ BC Cancer Agency, Vancouver, BC, Canada

${ }^{17}$ Department of Surgery, The University of British Columbia, Vancouver, BC, Canada

${ }^{18}$ School of Medicine, Western Sydney University, NSW, Australia

${ }^{19}$ Cancer Research Division, Cancer Council NSW, Sydney, Australia

${ }^{20}$ Department of Surgery, Trinity College Dublin, Dublin, Ireland 


\section{Corresponding author:}

Eileen Morgan

Section of Cancer Surveillance

International Agency for Research on Cancer

150 cours Albert Thomas

69372 Lyon CEDEX 08, France

Email: MorganE@fellows.iarc.fr

Telephone: +33472738886

Word count:

Abstract - 250

Main text $-3,828$

Keywords: cancer survival; oesophageal cancer; international 


\section{Abstract}

Introduction: Survival from oesophageal cancer remains poor, even across high-income countries. Ongoing changes in the epidemiology of the disease highlight the need for survival assessments by its two main histological subtypes, adenocarcinoma (AC) and squamous cell carcinoma (SCC).

Methods: The ICBP SURVMARK-2 project, a platform for international comparisons of cancer survival, collected cases of oesophageal cancer diagnosed 1995-2014, followed until 31 $1^{\text {st }}$ December 2015, from cancer registries covering seven participating countries with similar access to health care (Australia, Canada, Denmark, Ireland, New Zealand, Norway and the UK). 1- and 3-year age-standardised net survival alongside incidence rates were calculated by country, subtype, sex, age group and period of diagnosis.

Results: 111,894 cases of AC and 73,408 cases of SCC were included in the analysis. Marked improvements in survival were observed over the 20-year period in each country, particularly for AC, younger age groups and 1-year after diagnosis. Survival was consistently higher for both subtypes in Australia and Ireland followed by Norway, Denmark, New Zealand, the UK and Canada. During 20102014, survival was higher for AC compared to SCC, with 1-year survival ranging from $46.9 \%$ (Canada) to $54.4 \%$ (Ireland) for AC and $39.6 \%$ (Denmark) to $53.1 \%$ (Australia) for SCC.

Conclusion: Marked improvements in both oesophageal AC and SCC survival suggest advances in treatment. Less marked improvements 3 years after diagnosis, among older age groups and patients with SCC, highlight the need for further advances in early detection and treatment of oesophageal cancer alongside primary prevention to reduce the overall burden from the disease.

\section{Summary Box}

\section{What is already known about this subject?}


- Survival from oesophageal cancer remains poor, even across high-income countries.

- In light of differences in the descriptive epidemiology and the degree of treatment advances of the two main histological groups (adenocarcinoma and squamous cell carcinoma), it is important to assess survival stratified by subtype and to benchmark this across countries and over time.

\section{What are the new findings?}

- Using data from high-quality population-based cancer registries from countries with similar healthcare access (Australia, Canada, Denmark, Ireland, New Zealand, Norway, and the United Kingdom (UK), this study investigates trends in survival of oesophageal cancer by histological subtype.

- Overall, improvements in survival in both subtypes were observed during the 20-year study period, with some countries showing greater improvements than others. Marked survival increases more noted for adenocarcinoma, younger age groups and at 1-year post-diagnosis.

- Certain geographical variations in survival were observed, with consistently higher survival for both subtypes in Australia and Ireland followed by Norway, Denmark, New Zealand, the UK and Canada.

\section{How might it impact on clinical practice in the foreseeable future?}

- These study findings highlight the impact of treatment advances on oesophageal cancer survival, and the importance of continued advances in treatment options, particularly among older patients, as well as continued surveillance to benchmark survival across countries.

- While oesophageal cancer survival has been increasing across countries in recent years, it remains low for both disease subtypes. As such, future research into early detection and treatment, alongside primary prevention is warranted to improve survival and reduce the disease burden.

\section{Introduction}

Oesophageal cancer is the seventh most common cancer worldwide with close to 600,000 new cases diagnosed in 2018 and the sixth most common cause of cancer mortality, with more than half a million deaths.[1] The disease is predominantly categorised by two main histological subtypes with distinct aetiologies: adenocarcinoma (AC), which is typically located in the lower third of the oesophagus and 
linked to Barrett's oesophagus (characterised by metaplastic epithelium), and squamous cell carcinoma (SCC), which develops in the native oesophageal epithelium. While SCCs are associated with smoking and alcohol consumption, ACs mainly occur in patients with a history of gastro-oesophageal reflux disease (GORD), which in turn is associated with obesity. [2,3] Recent studies have shown that although SCC is the more common type of oesophageal cancer globally, incidence rates of AC have surpassed SCC rates in high-income countries.[4] These changes may relate to an increasing prevalence of obesity and GORD and a concurrent decline in Helicobacter pylori infection (changes in AC incidence) and declines in tobacco smoking prevalence (changes in SCC incidence).

Over the last two decades there have been marked advances in the diagnosis and treatment of oesophageal cancer with an increasing use of multimodality treatments. Recent randomised controlled trials have reported improvements in survival for patients with clinically-resectable cancer undergoing neoadjuvant chemoradiotherapy plus surgery, compared to surgery alone.[5,6] Subsequent to these trials, preoperative chemotherapy plus chemoradiotherapy followed by surgery has become a standard treatment modality, with more intensive perioperative chemotherapy used since publication of the MRC Adjuvant Gastric Infusional Chemotherapy (MAGIC) trial in 2007[7] and the FLOT trial in 2019.[8] In addition, positron emission tomography computed tomography (PET-CT) scanning has been found to improve staging of oesophageal cancer and this has provided better guidance for stage-specific treatment.[9]

Notwithstanding, overall survival from oesophageal cancer remains low - 5 -year survival peaks $24 \%$ in high-income countries - as a result of a large proportion of patients with advanced stage at diagnosis, with some not undergoing radical treatment due to comorbidities.[10] Previous population-based studies have suggested that 1-year survival is higher among patients diagnosed with AC compared to patients with SCC, but these studies have been conducted either at an individual country level, [1114] or have not had sufficiently recent follow-up to reflect recent changes in treatment.[15]

The ICBP SURVMARK-2 project, a multidisciplinary partnership gathering experts and data from seven countries characterised by having similar access to healthcare, aims to investigate and elucidate differences in cancer survival across high-income settings. In this paper, we report trends in oesophageal cancer incidence and survival by histological subtype for seven countries with over 20 years of data, investigating subtype-specific survival differences by period of diagnosis, country, age group and sex.

\section{Methods}

Data collection

As part of the ICBP SURVMARK-2 project data for primary cancers of the oesophagus were obtained from 21 population-based cancer registries spanning seven countries: Australia (New South Wales, Victoria, Western Australia), Canada (Alberta, British Columbia, Manitoba, New Brunswick, Newfoundland and Labrador, Nova Scotia, Ontario, Prince Edward Island, Quebec, Saskatchewan), Denmark, Ireland, New Zealand, Norway and the UK (England, Scotland, Wales and Northern Ireland). Cases diagnosed during 1995-2014 (Ireland 1995-2013) and followed up until 31 ${ }^{\text {st }}$ December 2015 were included in the analysis. Data from two Canadian registries were excluded as data were only available from 2000 (Quebec) or death linkage was not systematically carried out prior to 2005 
(Newfoundland and Labrador). A total of 19 jurisdictions from seven countries thus contributed data in the present analyses.

\section{Case Definition}

Primary malignant oesophageal tumours (ICD-10: C15) were included. Histological groups were based on the International Classification of Diseases for Oncology, third edition (ICD-O-3) [16] and defined as ACs: 8140-8141, 8143-8145, 8190-8231, 8260-8263, 8310, 8401, 8480-8490, 8550-8551, 8570-8574 and 8576; SCCs: 8050-8078 and 8083-8084; Unspecified: 8000-8005. All remaining morphology codes were grouped as "Other", with the exception of gastrointestinal stromal (ICD-O-3: 8936) and neuroendocrine tumours (ICD-O-3: 8013, 8041-8045, 8150-8158, 8240-8247, 8249, and 8574) which were excluded from all analyses as they differ in their aetiology and prognosis from other oesophageal tumours.

In total, 216,689 cases of oesophageal cancer were provided from the 19 included jurisdictions, of which 185,796 patients diagnosed with either AC or SCC were identified. Cases younger than 15 or older than 99 years at diagnosis, cases diagnosed based on death certificates only (DCOs) or at autopsy as well as those with multiple primaries at the same site, were excluded $(n=494 ; 0.3 \%)$. This resulted in a total of 185,302 patients included in the survival analyses.

Ethical approval was obtained from the International Agency for Research on Cancer (IARC) Ethics Committee, as well as from the relevant ethics committees in each participating jurisdiction, as required.

\section{Statistical analysis}

Trends in age-standardised incidence rates per 100,000 person-years were calculated for the two main histological subgroups (AC and SCC) of oesophageal cancer using the World Standard Population.[17] Net survival, defined as the survival of patients from the specific cancer under study after controlling for other causes of death, was used to benchmark across countries. Age-standardised net survival estimates at 1 and 3 years after diagnosis and their 95\% confidence intervals (Cls) were calculated for AC and SCC and for each 5-year period of diagnosis by age group (15-64 years, 65-74 years and 75-99 years), sex and country; the unbiased Pohar Perme estimator [18] was used to take into account the higher competing risks of death among the older populations. Analyses were performed using the stnet command in Stata version 14.2 and the International Cancer Survival Standard (ICSS) weights were used for age standardization.[19]

The cohort approach was used for the earlier three periods of diagnosis (1995-1999, 2000-2004 and 2005-2009) where complete follow-up was available, whereas the period approach [20] was used for the most recent diagnosis period (2010-2014) to estimate 3-year survival for patients without the complete three years follow-up.

Life tables were constructed for each jurisdiction for all-cause mortality in the general population by sex, single year of age and calendar year during 1995-2014. As it is possible that some cancers of the lower oesophagus may have been incorrectly recorded or misclassified as cancers of the gastric cardia 
(ICD-10: C16.0), additional incidence and survival analyses were performed by histological subtype combining C15 and C16.0 together for cases diagnosed 2010-2014.

\section{Patient and Public Involvement}

As this work is a retrospective study involving examination of secondary cancer data only, patients were not involved in the design and conduct of this research.

\section{Results}

In total, 111,894 new cases of AC and 73,408 cases of SCC diagnosed 1995-2014 were included in the survival analysis. While AC was more common in males than females, sex-specific differences were less marked for SCC (Table 1). The median age at diagnosis ranged from 66 to 72 years (across countries) for AC and from 65 to 75 years for SCC. During the period of diagnosis 1995-1999, SCC was the most common subtype across all countries, except for the UK. Subsequently the proportion of AC increased over time and became the most common subtype in all countries during the most recent period (2010-2014), ranging from $50.9 \%$ of all cases in Ireland to $59.9 \%$ in the UK, whereas the proportion of SCC concomitantly decreased over time, with proportion ranging from $29.8 \%$ in the UK to $43.3 \%$ in Denmark (2010-2014) (Figure 1). While the proportion of other histological types were relatively small and constant over time, cases with unspecified histology were relatively high in some countries, particularly during earlier periods of diagnosis, ranging from $9.5 \%$ of cases in Norway to $21.7 \%$ of cases in the UK during 1995-1999, with decreasing proportions observed thereafter.

Age-standardised incidence rates of oesophageal AC increased in all seven countries over the 19952014 period, surpassing the rates of SCC which were in decline in all countries except Denmark (Supplementary Figure S1). In 2014, age-standardised incidence rates of oesophageal AC were highest in the UK (7.7 per 100,000 person-years) and oesophageal SCC rates highest in Denmark (3.6 per 100,000 person-years). In 2013 (incidence data available from all participating countries), oesophageal SCC rates were highest in Ireland (4.4 per 100,000 person-years). Canada had the lowest incidence of both oesophageal AC and SCC in 2014 (2.7 and 1.2 per 100,000 person-years, respectively). Sensitivity analyses showed that the increasing incidence rates of oesophageal $A C$ were similar to the corresponding trends of $\mathrm{AC}$ of the gastric cardia over time, except for the UK, where incidence rates decreased rather than increased to 2.5 per 100,000 person-years in 2014.

\section{Adenocarcinoma vs squamous cell carcinoma survival}

1-year and 3-year survival increases were greater for AC, reaching 21.9 (Ireland) and 14.5 (Denmark) percentage points over the 20-year period, respectively, compared with 15.6 (Ireland) and 13.3 (Norway) percentage points for SCC (Figure 2, Supplementary Table S1). In the most recent period, 1year survival tended to be greater for AC than SCC across countries with the observed differences greater in Norway $(53.2 \%$ vs. $40.0 \%, 13.2 \%$ point difference), Denmark $(50.7 \%$ vs. $39.6 \%, 11.1 \%$ difference) and in the UK ( $50.6 \%$ vs. $43.4 \%$, respectively or $7.2 \%$ difference). Subtype differences were less apparent at 3 years after diagnosis.

\section{Survival from adenocarcinoma of the oesophagus}

There were marked improvements in 1-year net survival from AC across countries in patients diagnosed during 2010-2014 relative to 1995-1999, with increases ranging from 7.5 to 21.9 percentage 
points, with the largest increases observed in Ireland, Norway, Denmark and the UK. In the most recent period, 1-year net survival was highest in Ireland (54.4\%), Australia (53.6\%) and Norway (53.2\%) but somewhat lower in Canada (46.9\%) and New Zealand (48.2\%) (Figure 2, Supplementary Table S1). Absolute improvements in 3-year survival from AC ranged from 6.0 (Canada) to 14.5 (Denmark) percentage points, with the highest survival observed in Australia (29.1\%) and Ireland (28.4\%), with somewhat lower survival estimates seen in Canada (21.5\%) and the UK (22.8\%) in 2010-2014.

Survival varied considerably by age at diagnosis. While 1 -year net survival from AC ranged from $51.7 \%$ (New Zealand) up to 69.0\% (Ireland) in patients diagnosed at age 15-64 years in 2010-2014, the range was $36.9 \%$ (Denmark and UK) to $44.1 \%$ (Australia) in those aged 75 years and above. Marked improvements were observed in 1-year survival from AC in patients below 65 years (ranging from 9.2 (Canada) to 30.3 (Ireland) percentage points across the seven countries) and 65-74 years at diagnosis (ranging from 6.1 (Canada) to 22.4 (Denmark) percentage points) over the 1995-2014 period (Figure 3a, Supplementary Table S4). Less marked improvements in 1-year survival over time were observed in the oldest age group (75+ years) with the greatest improvements in Norway and the smallest observed in New Zealand (14.1 and 4.9 percentage points, respectively). Similar results were seen for survival at three years, where improvements were largest in the two younger age groups (Figure $\mathbf{3 b}$, Supplementary Table S5).

Improvements in 1- and 3-year net survival were observed in both males and females over time with higher survival observed in males compared to females in the majority countries (Canada, the UK, Denmark and Ireland) (Supplementary Table S3). Improvements in both 1-year and 3-year net survival were also observed at the jurisdiction level within countries, with the greatest absolute survival improvements among diagnoses 2010-2014 compared to 1995-1999 observed in Saskatchewan, Canada (27.8 percentage point increase at 1 year) and Northern Ireland, UK (11.9 percentage points at 3 years). Within country survival differences of up to 17.7 percentage points were observed at 1 year in Canada ranging from 36.1\% in Prince Edward Island to 53.8\% in Saskatchewan in 2010-2014 (Supplementary Table S2).

\section{Survival from squamous cell carcinoma of the oesophagus}

Improvements in 1-year net survival from oesophageal SCC were observed in all countries with survival increases ranging from 3.4 to 15.6 percentage points in Canada and Ireland, respectively (Figure 2, Supplementary Table S1). Improvements were slightly less pronounced at 3 years after diagnosis, with survival increases ranging from 3.1 percentage points (Canada) to 13.3 percentage points (Norway). In the most recent period, both 1- and 3-year survival from SCC was highest in Australia $153.1 \%$ and $28.5 \%$, respectively).

Survival from SCC 1 year after diagnosis particularly improved among patients aged under 65 years and between 65 and 74 years, with marked improvements seen in the UK and Denmark as well as in Norway and Ireland (the latter two countries only for 65-74 year olds) (Figure 3a, Supplementary Table S4). Improvements were also observed in Australia, Ireland, New Zealand and the UK for patients aged 75 years and older at diagnosis, with the increases ranging from 10.1 to 15.2 percentage point in 1-year survival. Overall, similar trends were observed in 3-year survival, although only minor improvements were seen among SCC patients diagnosed at ages 75 and older (Figure 3b, Supplementary Table S5). 
For both sexes, 1- and 3-year net survival from SCC improved over the 20-year period (Supplementary Table S3). Survival estimates were higher in females compared to males, most notably in Australia (39.0\% versus $22.3 \% 3$-year survival, respectively) and the UK (24.1\% versus $16.4 \% 3$-year survival; $48.1 \%$ versus $39.0 \% 1$-year survival, respectively).

Improvements in both 1-year and 3-year net survival from SCC were also observed at the individual jurisdiction level by up to 22.4 percentage points at 1 year (New Brunswick, Canada) and 18.7 percentage points at 3 years (Victoria, Australia) over the 20-year period. Within-country differences in survival were observed in the most recent period of up to 34.1 percentage points at 1 year in Canada, ranging from $23.6 \%$ in Nova Scotia to $57.7 \%$ in New Brunswick (Supplementary Table S2).

\section{Sensitivity analyses: Survival from oesophageal adenocarcinoma and gastric cardia cancer}

Similar patterns in 1-year survival of oesophageal AC across countries were observed when cancers of the gastric cardia were additionally included in the analyses and compared with survival from oesophageal AC alone. There was minor change in survival estimates for the 2010-14 period when 7,390 gastric cardia cancers were included, with the largest increase of 3 percentage points seen in AC survival in Australia (56.6\%) (Supplementary Figure S2).

\section{Discussion}

With the incidence of AC of the oesophagus rising over the past 20 years, the subtype has become the most common type of oesophageal cancer in all seven high-income countries included in this study. In contrast, the incidence of SCC has been steadily decreasing over the same period. We report that survival from both oesophageal AC and SCC have improved substantially across all countries, with survival from AC generally more favourable than that of SCC, with differences of up to 13.2 percentage points for 1-year survival for patients diagnosed in 2010-2014. Generally, improvements in survival were most pronounced in patients diagnosed with AC compared to SCC among patients aged $<75$ years at diagnosis, and for 1-year survival compared to 3-year survival. Similar improvements were seen within countries, for example in New South Wales, Australia 1-year survival of AC improved by over 12 percentage points compared to an improvement of less than 2 percentage points in SCC patients. Whilst improvements in 1-year net survival of AC were greatest in Ireland, Norway and Denmark, recent survival estimates were highest in Ireland, Australia and Norway. Similar patterns were observed for oesophageal SCC with some within-country variation.

Survival from AC was higher relative to that of SCC, particularly at 1-year after diagnosis. Similar findings have been reported previously $[15,21]$, with the differences in the aetiology and consequent comorbidity postulated as one possible explanatory factor: as smoking is a strong risk factor of SCC, and is often associated with other comorbidities such as cardiovascular and respiratory disease, this might in part influence survival of these patients and explain the poorer prognosis. [22] Future studies are needed to investigate survival differences between the two subtypes with an assessment of comorbidities. Furthermore, patients with Barrett's oesophagus (a precursor lesion of AC) who undergo endoscopic surveillance may be diagnosed at an earlier stage, which may in turn partially account for the relatively higher AC survival..[23,24] The true impact of active surveillance using endoscopy remains unclear however, with a previous meta-analysis of non-randomized studies reporting only a small benefit in survival, although these results are susceptible to confounding biases.[25] Recent studies have shown the promise of less invasive techniques (e.g. sponges) for the 
early detection of oesophageal AC [26] which may also prove useful in the detection of oesophageal squamous dysplasia, a precursor to oesophageal SCC. [27]

Nonetheless, survival for both oesophageal cancer types remains poor. As such, it is important that international initiatives and campaigns targeting obesity control through healthy diet and regular physical activity, alongside continued reduction of smoking and the harmful use of alcohol,[28] continue to be promoted to further reduce the overall incidence of oesophageal cancer. Further research on chemopreventative therapies[29] such as aspirin and proton-pump inhibitors as well as endoscopic intervention and ablative therapies for precancerous conditions may also prove beneficial in reducing the burden of disease.

The marked improvements in survival from both subtypes are likely related to the improvement and further development of treatments for oesophageal cancer that have been adopted in recent years, including the use of neo-adjuvant therapy for resectable, locally-advanced oesophageal cancers $[5,7,30,31]$ as well as better supportive care in terms of nutrition. The main curative treatment strategy for oesophageal cancer (both AC and SCC) relies on surgical approaches, or in some cases definitive chemo-radiotherapy for SCC,[32] with recent randomised trials showing improved survival with the addition of neoadjuvant chemotherapy or chemo-radiotherapy.[5,30-33] The CROSS trial has shown that compared with surgery alone, treatment of locally advanced oesophageal cancer with chemo-radiotherapy followed by surgery improved overall 5-year survival from $33.3 \%$ to $43.3 \%$ and from $30.2 \%$ to $61.0 \%$ in resectable patients with AC and SCC, respectively.[5] Furthermore, the more intensive perioperative MAGIC regimen, may have contributed to improved survival in oesophageal AC patients over the last decade,[7] and the recent FLOT randomised trial highlights potential continued progress in this context.[8]

A second key factor may be increased centralisation of oesophageal cancer surgery.[11] Many of the countries involved in this study such as Denmark (2007), Norway (2013), England and Wales (2000; 2007) and Ireland (2006) have undergone major national health reforms. These reforms have resulted in increased expenditure on cancer services and centralisation of surgery resulting in a shortening of time until diagnosis and the fast-tracking of treatment and ultimately improvements in populationbased survival.[34-38] Survival differences observed within countries could be due to limited availability of specialised care in oesophageal cancer services in lower incidence regions and warrant further investigation. In addition, improvements in diagnostic and staging procedures through the use of PET-CT [39] could also have contributed to improved prognosis as a result of more accurate staging of patients which has been a possible explanation for improved survival in a previous study.[11] An indepth investigation of how survival differences in oesophageal cancer could partly be explained by variation in the proportion of histological subtype and earlier diagnosis, i.e. stage at diagnosis, is the subject of a separate ICBP SURVMARK-2 paper. Future studies should aim to diagnose cases in highrisk populations earlier and identify biomarkers that aid the characterisation of high-risk SCC patients. [27] In addition, the recent identification of mutational signatures of oesophageal AC, show promise for early detection, and more targeting of treatments for patients [40] which may further improve survival outcomes.

While marked survival improvements were observed in the younger age groups diagnosed below the age of 75 years, improvements in older patients were less evident. As older patients are more likely to present with comorbidities than younger patients, treatment decisions or adherence to treatment 
in this age group often differ, which may reduce the prospects of treatment-related improvements in survival.[41] A lack of clinical guidelines for this age group across jurisdictions might also impact survival outcomes. Age-related inequalities have been identified for colon cancer[42] and the survival gap between elderly and middle-aged patients has been widening in Europe, particularly after the first year of diagnosis, an indication of differing treatment decisions in this cohort.[43] As around $40 \%$ of AC and SCC patients are diagnosed at ages greater than 75 years, there is a need for randomised controlled trials targeting older cancer patients to investigate the efficacy of cancer treatments in this age group and for clinicians to use comprehensive geriatric assessments when making treatment decisions in these patients.[44]

This international study, part of the ICBP SURVMARK-2 project, has a number of strengths. As an international partnership, data have been collected from 21 high-quality cancer registries allowing assessment of cancer survival among a large number of AC and SCC patients over a 20-year period. The procedures in place under this collaborative project have ensured that data are of both optimal quality and comparability across countries. Detailed protocols for the collection and linkage of data were established and each registry dataset was examined to confirm adherence, with any queries discussed with each registry and re-evaluated datasets submitted, where necessary; frequent discussions with local leads and clinicians were also scheduled. Although measures have been put in place to ensure data are consistent, it is possible that differences in clinical practices and cancer registration practices including coding and classification may have contributed to the observed differences in survival across countries. It may be that as diagnostic techniques have improved, the quality of cancer registrations has further increased, which in turn may have led to the observed decline of the proportions of oesophageal cancers with unspecified histology. However, the proportion of unspecified oesophageal cancers is relatively low particularly for the more recent time periods, ranging from $4.5 \%$ in Denmark to $11.4 \%$ in New Zealand among patients diagnosed in 2010 2014. As such, the major conclusions of our paper are likely to remain valid.

It is also possible that some $A C$ of the lower oesophagus and gastro-oesophageal junction were misclassified as cancers of the gastric cardia (ICD-10 C16.0) which were not included in the main analyses, as it was not possible to differentiate these cases without information on Siewert type.[45,46] However, after including cases coded as C16.0, which includes both gastric cardia and gastro-oesophageal junction cancers, there was little impact on survival estimates and overall patterns across countries for both histological subtypes. To avoid misclassification of cancers of the gastrooesophageal junction, a new topography code for these cancers to separate from gastric cardia cancers should be considered. Lastly, this study did not have treatment-specific data to directly quantify the impact of specific treatment advances on improved survival over time.

In conclusion, the international variation observed in survival from oesophageal AC and SCC points to a large role of improved treatment and management of cases across the seven countries included in the ICBP SURVMARK-2 project. Given the ongoing changes in the epidemiology and treatment of oesophageal cancer, with the incidence of AC surpassing that of SCC and constant advances in therapeutic modalities, ongoing surveillance and additional studies are warranted, particularly those that focus on older patients, for whom survival has least improved. An increasing emphasis on the early detection of precancerous changes and early cancers to identify AC among high-risk groups, as well as broad prevention measures, are crucial to reduce the number of oesophageal cancer diagnoses and improve survival among patients in future years. 


\section{SurvMark-2 Acknowledgements and funders}

The authors would like to thank the ICBP management team of Cancer Research UK for managing the program, the ICBP SurvMark-2 Local Leads for advice to understand the data, for their contributions to the study protocol and interpretation of the results and the ICBP Clinical Committees for their advice. We are also grateful to the ICBP SurvMark-2 Academic Reference Group for providing independent peer review and advice for the study protocol and analysis plan development. Finally we are thankful to the ICBP Program Board for their oversight and direction. The ICBP is funded by the Canadian Partnership Against Cancer; Cancer Council Victoria; Cancer Institute New South Wales; Cancer Research UK; Danish Cancer Society; National Cancer Registry Ireland; The Cancer Society of New Zealand; NHS England; Norwegian Cancer Society; Public Health Agency Northern Ireland, on behalf of the Northern Ireland Cancer Registry; The Scottish Government; Western Australia Department of Health; Wales Cancer Network.

Where authors are identified as personnel of the International Agency for Research on Cancer / World Health Organization, the authors alone are responsible for the views expressed in this article and they do not necessarily represent the decisions, policy or views of the International Agency for Research on Cancer / World Health Organization.

Competing interests: The authors declare no relevant competing interests

\section{Contributorship statement}

Study concept and design: EM, IS, FB, MA. Data collection and interpretation of data: HT, LS, RW, SK, $A L, P D, V T, G E, A G, E M, P W, S V, C J, B M, O B$. Data analysis: EM, MR, AB, JF. Drafting the manuscript: $E M, I S, M A$. Critical revision of the manuscript for manuscript for important intellectual content: all authors.

ICBP SurvMark-2 Local Leads:

Al Artaman, CancerCare Manitoba, Winnipeg, Manitoba, Canada;

Alana Little, Cancer Institute NSW, Alexandria, New South Wales, Australia;

Andy Deas, Information Services Division, NHS National Services, Edinburgh, Scotland, United Kingdom;

Angela Eckstrand, Alberta Health Services, Edmonton, Alberta, Canada;

Anna Gavin, Northern Ireland Cancer Registry, Queen's University Belfast, Belfast, Northern Ireland, United Kingdom;

Bin Zhang, Government of New Brunswick, Fredericton, New Brunswick, Canada;

Bjørn Møller, Cancer Registry of Norway (Kreftregisteret), Oslo, Norway;

Carol McClure, Government of Prince Edward Island, Charlottetown, Prince Edward Island, Canada;

Ceri White, Welsh Cancer Intelligence \& Surveillance Unit, Public Health Wales, Cardiff, Wales, United Kingdom; 
Christine Bertrand, Government of Quebec, Montreal, Quebec, Canada;

Christopher Jackson, Cancer Society of New Zealand, Wellington, New Zealand;

Cindy Stock, BC Cancer, Vancouver, British Columbia, Canada

Claire Austin, Ministry of Health, New Zealand

David H Brewster, Centre for Population Health Sciences, Edinburgh University, Edinburgh, Scotland, United Kingdom;

David S Morrison, Scottish Cancer Registry, University of Glasgow, Scotland;

David Ransom, Department of Health, Perth, Western Australia, Australia;

Deirdre Fitzpatrick, Northern Ireland Cancer Registry, Queen's University Belfast, Belfast, Northern Ireland, United Kingdom;

Donna Turner, CancerCare Manitoba, Winnipeg, Manitoba, Canada;

Dyfed Huws, Welsh Cancer Intelligence \& Surveillance Unit, Public Health Wales, Cardiff, Wales, United Kingdom;

Eshwar Kumar, Government of New Brunswick, Fredericton, New Brunswick, Canada;

Farah McCrate, Eastern Health, St. John's, Newfoundland and Labrador, Canada;

Gail Noonan, CancerCare Manitoba, Winnipeg, Manitoba, Canada;

Geoff Porter, Canadian Partnership Against Canada, Toronto, Ontario, Canada;

Gerda Engholm, The Danish Cancer Society (Kræftens Bekæmpelse), Copenhagen, Denmark;

Gina Lockwood, Canadian Partnership Against Canada, Toronto, Ontario, Canada;

Grace Musto, CancerCare Manitoba, Winnipeg, Manitoba, Canada;

Grlica Bolesnikov, Government of New Brunswick, Fredericton, New Brunswick, Canada;

Guillaume Ruel, Government of Quebec, Montreal, Quebec, Canada;

Hanna Tervonen, Cancer Institute NSW, Alexandria, New South Wales, Australia;

Hazem Abd Elkader, Cancer Society of New Zealand, Wellington, New Zealand;

Heather Stuart-Panko, Saskatchewan Cancer Agency, Regina, Saskatchewan, Canada;

Helen Farrugia, Cancer Council Victoria, Melbourne, Victoria, Australia;

Janet Warlow, Welsh Cancer Intelligence \& Surveillance Unit, Public Health Wales, Cardiff, Wales, United Kingdom;

Jason Poole, Public Health England, London, England, United Kingdom; 
Jes Søgaard, The Danish Cancer Society (Kræftens Bekæmpelse), Copenhagen, Denmark;

Jingyu Bu, Alberta Health Services, Edmonton, Alberta, Canada;

John Dowling, Department of Health, Perth, Western Australia, Australia;

John Spinelli, BC Cancer, Vancouver, British Columbia, Canada;

Kim Vriends, Government of Prince Edward Island, Charlottetown, Prince Edward Island, Canada;

Lorraine Shack, Alberta Health Services, Edmonton, Alberta, Canada;

Louise Sandford, Cancer Society of New Zealand, Wellington, New Zealand;

Marianne Brenn Jerm (Cancer Registry of Norway (Kreftregisteret), Oslo, Norway

Mary Jane King, Cancer Care Ontario, Toronto, Ontario, Canada;

Maureen Maclntyre, Nova Scotia Health Authority, Halifax, Nova Scotia, Canada;

Nathalie St-Jacques, Nova Scotia Health Authority Cancer Care Program, Halifax, Nova Scotia, Canada;

Nicole Mittmann, Cancer Care Ontario, Toronto, Ontario, Canada;

Paul Walsh, National Cancer Registry Ireland, Cork, Ireland;

Prithwish De, Cancer Care Ontario, Toronto, Ontario, Canada;

Raman Agnihotram, McGill University Health Centre, Montreal, Quebec, Canada;

Richard Walton, Cancer Institute NSW, Alexandria, New South Wales, Australia;

Richard Trevithick, Department of Health, Perth, Western Australia, Australia;

Rory Carle, Department of Health, Perth, Western Australia, Australia;

Ryan Woods, BC Cancer, 675 W 10th Ave, Vancouver, BC V5Z 1L3, Canada;

Sally Vernon, Public Health England, London, England, United Kingdom;

Serena Kozie, Saskatchewan Cancer Agency, Regina, Saskatchewan, Canada;

Susan Ryan, Eastern Health, St. John's, Newfoundland and Labrador, Canada;

Suzanne Leonfellner, Government of New Brunswick, Fredericton, New Brunswick, Canada;

Vicky Thursfield, Cancer Council Victoria, Melbourne, Victoria, Australia;

ICBP SurvMark-2 Academic Reference Group:

Brian Rous, Public Health England, London, United Kingdom; 
Diana Sarfati, University of Otago, Dunedin, New Zealand;

Dianne O'Connell, Cancer Council NSW, Sydney, New South Wales, Australia;

Michael Eden, Public Health England, London, United Kingdom;

Sabine Siesling (Netherlands Comprehensive Cancer Organisation (IKNL), Utrecht, The Netherlands) and University of Twente, Enschede, The Netherlands).

ICBP Clinical Committee - Upper GI

Alan Christie, Edinburgh Cancer Centre, Scotland, United Kingdom;

Andrew Kennedy, Association of Laparoscopic Surgeons, Ireland;

Ashley Roberts, Cardiff \& Vale University Health Board, Wales, United Kingdom;

Asif Chaudry, The Royal Marsden, London, United Kingdom;

Carys Morgan, Velindre Cancer Centre, Wales, United Kingdom;

Christian Finley, McMaster University, Canada;

David Ransom, Fiona Stanley Hospital, Western Australia;

Geoff Porter, Dalhousie University, Nova Scotia, Canada;

John Reynolds, St James Hospital and Trinity College, Dublin, Ireland;

John Windsor, University of Auckland and Auckland City Hospital, New Zealand;

John Zalcberg, School of Public Health and Preventive Medicine at Monash University, Australia;

Natalie Coburn, Odette Cancer Centre, Canada;

Naureen Starling, The Royal Marsden, London, United Kingdom;

Neil Merrett, University of Western Sydney and South Western Sydney Local Health District, Australia;

Paulose George, Wrexham Maelor Hospital, Wales, United Kingdom;

Piers Gatenby, Royal Surrey County Hospital, Surrey, United Kingdom;

Tom Crosby, Velindre Cancer Centre and South Wales Cancer Network, Wales, United Kingdom;

Wyn Lewis, Cardiff and Vale University Health Board, Wales, United Kingdom; 
ICBP Programme Board:

Aileen Keel, Scottish Government, Edinburgh, Scotland, UK;

Anna Gavin, Queen's University Belfast, Belfast, Northern Ireland, United Kingdom;

David Fitzgerald, National Cancer Programme Director, NHS England, England, United Kingdom;

Christopher Jackson, Cancer Society of New Zealand, Wellington, New Zealand;

Conan Donnelly, National Cancer Registry Ireland, Cork, Ireland;

David Currow, Cancer Institute NSW, Alexandria, News South Wales, Australia;

David Ransom, Department of Health, Western Australia, Perth, Western Australia, Australia;

Gareth Davies, Wales Cancer Network, Cardiff, Wales, United Kingdom;

Geoff Porter, Canadian Partnership Against Canada, Toronto, Ontario, Canada;

Heather Bryant, Canadian Partnership Against Cancer, Toronto, Ontario, Canada;

Linda Aagaard Thomsen, Danish Cancer Society, Copenhagen, Denmark;

Kathryn Whitfield, Department of Human Services, Melbourne, Victoria, Australia;

Mike Kernaghan, Cancer Society of New Zealand, Wellington, New Zealand;

Nicole Mittmann, Cancer Care Ontario, Toronto, Ontario, Canada;

Ole Alexander Opdalshei, Norwegian Cancer Society, Oslo, Norway;

Robert Thomas, University of Melbourne, Melbourne, Victoria, Australia;

Sara Hiom, Cancer Research UK, England, United Kingdom;

Violet Platt, Department of Health, Western Australia, Perth, Western Australia, Australia; 

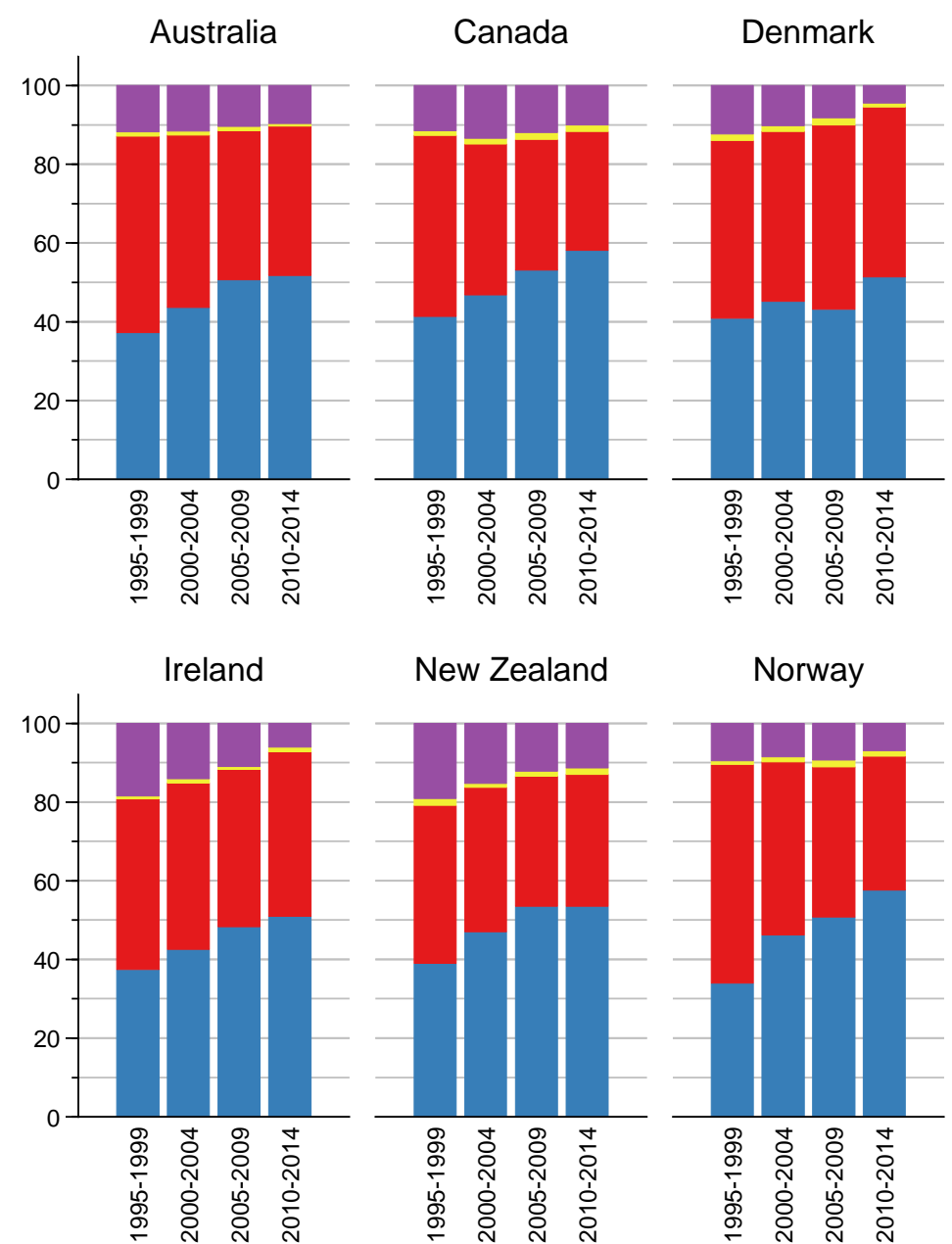

UK

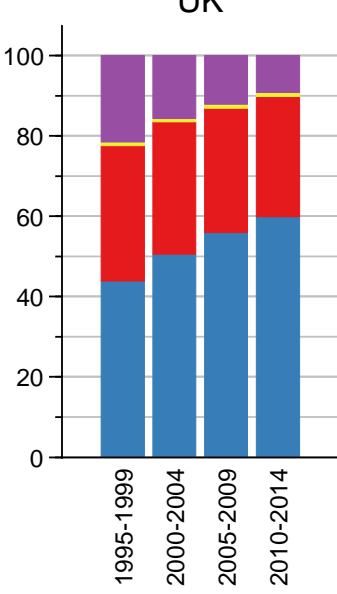

$\mathrm{AC}$ SCC

Other Unspecified

Figure 1: Proportion of oesophageal cancer cases by histological subtype and period of diagnosis, 1995-2014

*Morphological subtype categorised as AC: Adenocarcinoma of the oesophagus, SCC: Squamous cell carcinoma of the oesophagus, Other and Unspecified 
Table 1: Number and characteristics of new cases of oesophageal cancer (C15) by histological subtype, period of diagnosis and country, $1995-2014$

\begin{tabular}{|c|c|c|c|c|c|c|c|c|c|c|c|c|c|c|c|c|c|}
\hline \multirow[b]{2}{*}{ Country } & \multirow[b]{2}{*}{$\begin{array}{l}\text { Period of } \\
\text { diagnosis }\end{array}$} & \multicolumn{4}{|c|}{ Adenocarcinoma (AC) } & \multicolumn{4}{|c|}{ Squamous cell carcinoma (SCC) } & \multicolumn{4}{|c|}{ Other } & \multicolumn{4}{|c|}{ Unspecified } \\
\hline & & Cases & $\begin{array}{c}\text { Cases } \\
\text { included }(\%)^{\star}\end{array}$ & $\begin{array}{l}\text { Median } \\
\text { age }\end{array}$ & $\begin{array}{c}\% \\
\text { males }\end{array}$ & Cases & $\begin{array}{c}\text { Cases } \\
\text { included }(\%)^{*}\end{array}$ & $\begin{array}{l}\text { Median } \\
\text { age }\end{array}$ & $\begin{array}{c}\% \\
\text { males }\end{array}$ & Cases & $\begin{array}{c}\text { Cases } \\
\text { included } \\
(\%)^{*}\end{array}$ & $\begin{array}{l}\text { Median } \\
\text { age }\end{array}$ & $\begin{array}{c}\% \\
\text { males }\end{array}$ & Cases & $\begin{array}{c}\text { Cases } \\
\text { included } \\
(\%)^{*}\end{array}$ & $\begin{array}{l}\text { Median } \\
\text { age }\end{array}$ & $\begin{array}{c}\% \\
\text { males }\end{array}$ \\
\hline \multirow{4}{*}{ Australia } & 1995-1999 & 1251 & 1249(99.8\%) & 71 & 82 & 1690 & $1686(99.8 \%)$ & 71 & 49 & 33 & $33(100 \%)$ & 72 & 58 & 399 & $360(90.2 \%)$ & 75.5 & 59 \\
\hline & 2000-2004 & 1662 & 1654(99.5\%) & 70 & 82 & 1672 & 1668(99.8\%) & 72 & 51 & 38 & $37(97.4 \%)$ & 67 & 65 & 441 & $375(85 \%)$ & 76 & 59 \\
\hline & 2005-2009 & 2145 & 2142(99.9\%) & 70 & 83 & 1604 & $1600(99.8 \%)$ & 73 & 54 & 43 & $43(100 \%)$ & 70 & 74 & 444 & $381(85.8 \%)$ & 78 & 62 \\
\hline & 2010-2014 & 2418 & 2410(99.7\%) & 69 & 84 & 1779 & $1772(99.6 \%)$ & 72 & 53 & 34 & $34(100 \%)$ & 70 & 71 & 451 & $352(78 \%)$ & 77 & 62 \\
\hline \multirow{4}{*}{ Canada } & 1995-1999 & 1900 & 1898(99.9\%) & 69 & 85 & 2119 & 2119(100\%) & 69 & 59 & 52 & $52(100 \%)$ & 68 & 75 & 531 & $464(87.4 \%)$ & 75 & 61 \\
\hline & 2000-2004 & 2524 & 2521(99.9\%) & 68 & 85 & 2030 & 2026(99.8\%) & 70 & 58 & 75 & 75(100\%) & 69 & 72 & 617 & $536(86.9 \%)$ & 75 & 66 \\
\hline & 2005-2009 & 3355 & 3352(99.9\%) & 67 & 84 & 2026 & $2025(100 \%)$ & 70 & 61 & 112 & $112(100 \%)$ & 67 & 78 & 646 & $571(88.4 \%)$ & 75 & 68 \\
\hline & 2010-2014 & 4324 & $4306(99.6 \%)$ & 66 & 85 & 2215 & $2197(99.2 \%)$ & 70 & 61 & 119 & $115(96.6 \%)$ & 69 & 73 & 648 & $549(84.7 \%)$ & 74 & 72 \\
\hline \multirow{4}{*}{ Denmark } & 1995-1999 & 702 & 688(98\%) & 70 & 82 & 778 & 753(96.8\%) & 65 & 63 & 29 & $29(100 \%)$ & 67 & 83 & 213 & 198(93\%) & 73 & 68 \\
\hline & $2000-2004$ & 880 & 875(99.4\%) & 70 & 81 & 843 & 837(99.3\%) & 66 & 62 & 28 & 27(96.4\%) & 60 & 85 & 200 & 190(95\%) & 74.5 & 72 \\
\hline & 2005-2009 & 863 & 860(99.7\%) & 71 & 79 & 940 & 933(99.3\%) & 65 & 65 & 37 & $36(97.3 \%)$ & 66 & 61 & 166 & $162(97.6 \%)$ & 71.5 & 65 \\
\hline & 2010-2014 & 1275 & $1274(99.9 \%)$ & 69 & 80 & 1074 & $1074(100 \%)$ & 67 & 66 & 22 & $22(100 \%)$ & 70 & 77 & 112 & $107(95.5 \%)$ & 72 & 71 \\
\hline \multirow{4}{*}{ Ireland } & 1995-1999 & 553 & $553(100 \%)$ & 69 & 76 & 642 & 640(99.7\%) & 70 & 50 & 12 & $12(100 \%)$ & 59 & 67 & 273 & $232(85 \%)$ & 78 & 56 \\
\hline & 2000-2004 & 690 & 689(99.9\%) & 70 & 80 & 688 & 685(99.6\%) & 69 & 47 & 16 & 16(100\%) & 67.5 & 81 & 230 & $196(85.2 \%)$ & 76 & 53 \\
\hline & 2005-2009 & 869 & $869(100 \%)$ & 68 & 78 & 719 & 718(99.9\%) & 70 & 49 & 15 & $15(100 \%)$ & 68 & 67 & 198 & 183(92.4\%) & 79 & 62 \\
\hline & 2010-2014 & 757 & 754(99.6\%) & 69 & 80 & 623 & 618(99.2\%) & 71 & 49 & 17 & $17(100 \%)$ & 66 & 59 & 90 & 82(91.1\%) & 76 & 59 \\
\hline \multirow{4}{*}{$\begin{array}{l}\text { New } \\
\text { Zealand }\end{array}$} & 1995-1999 & 373 & $373(100 \%)$ & 71 & 82 & 386 & 385(99.7\%) & 71 & 55 & 17 & $17(100 \%)$ & 74 & 65 & 184 & 179(97.3\%) & 75 & 58 \\
\hline & 2000-2004 & 554 & $553(99.8 \%)$ & 71 & 83 & 432 & 431(99.8\%) & 72 & 47 & 12 & $12(100 \%)$ & 71 & 50 & 180 & 172(95.6\%) & 78 & 61 \\
\hline & 2005-2009 & 690 & $690(100 \%)$ & 71 & 82 & 428 & $426(99.5 \%)$ & 75 & 45 & 15 & $15(100 \%)$ & 61 & 80 & 158 & 145(91.8\%) & 78 & 58 \\
\hline & 2010-2014 & 761 & $761(100 \%)$ & 71 & 84 & 479 & $479(100 \%)$ & 72 & 49 & 23 & $23(100 \%)$ & 69 & 87 & 162 & $156(96.3 \%)$ & 77 & 69 \\
\hline \multirow{4}{*}{ Norway } & 1995-1999 & 277 & $277(100 \%)$ & 72 & 82 & 454 & 450(99.1\%) & 69 & 68 & 8 & $8(100 \%)$ & 70 & 88 & 78 & 72(92.3\%) & 76 & 75 \\
\hline & 2000-2004 & 406 & 403(99.3\%) & 72 & 75 & 389 & 386(99.2\%) & 70.5 & 67 & 10 & 10(100\%) & 67 & 80 & 76 & 71(93.4\%) & 77 & 65 \\
\hline & 2005-2009 & 494 & 493(99.8\%) & 70 & 81 & 371 & $369(99.5 \%)$ & 68 & 64 & 17 & $17(100 \%)$ & 68 & 65 & 91 & $83(91.2 \%)$ & 75 & 65 \\
\hline & 2010-2014 & 721 & 717(99.4\%) & 69 & 82 & 425 & $420(98.8 \%)$ & 68 & 68 & 18 & $18(100 \%)$ & 78 & 50 & 88 & $77(87.5 \%)$ & 74 & 62 \\
\hline \multirow{4}{*}{ UK } & 1995-1999 & 14959 & 14925(99.8\%) & 71 & 75 & 11520 & 11480(99.7\%) & 71 & 45 & 249 & 248(99.6\%) & 69 & 65 & 7393 & $6857(92.7 \%)$ & 77 & 55 \\
\hline & 2000-2004 & 18778 & 18742(99.8\%) & 72 & 77 & 12225 & 12195(99.8\%) & 72 & 45 & 273 & 273(100\%) & 69 & 65 & 5855 & 5359(91.5\%) & 77 & 57 \\
\hline & 2005-2009 & 22223 & 22181(99.8\%) & 71 & 78 & 12299 & 12269(99.8\%) & 72 & 46 & 349 & $347(99.4 \%)$ & 70 & 67 & 4863 & $4365(89.8 \%)$ & 77 & 59 \\
\hline & 2010-2014 & 25731 & 25685(99.8\%) & 71 & 79 & 12811 & $12767(99.7 \%)$ & 72 & 47 & 474 & 472(99.6\%) & 71 & 63 & 3959 & $3480(87.9 \%)$ & 79 & 60 \\
\hline
\end{tabular}

*Reasons for exclusion include DCOs, cases diagnosed at autopsy, data inconsistencies (dates, invalid age), under 15 or over 99 years at diagnosis, missing/ incomplete dates. 


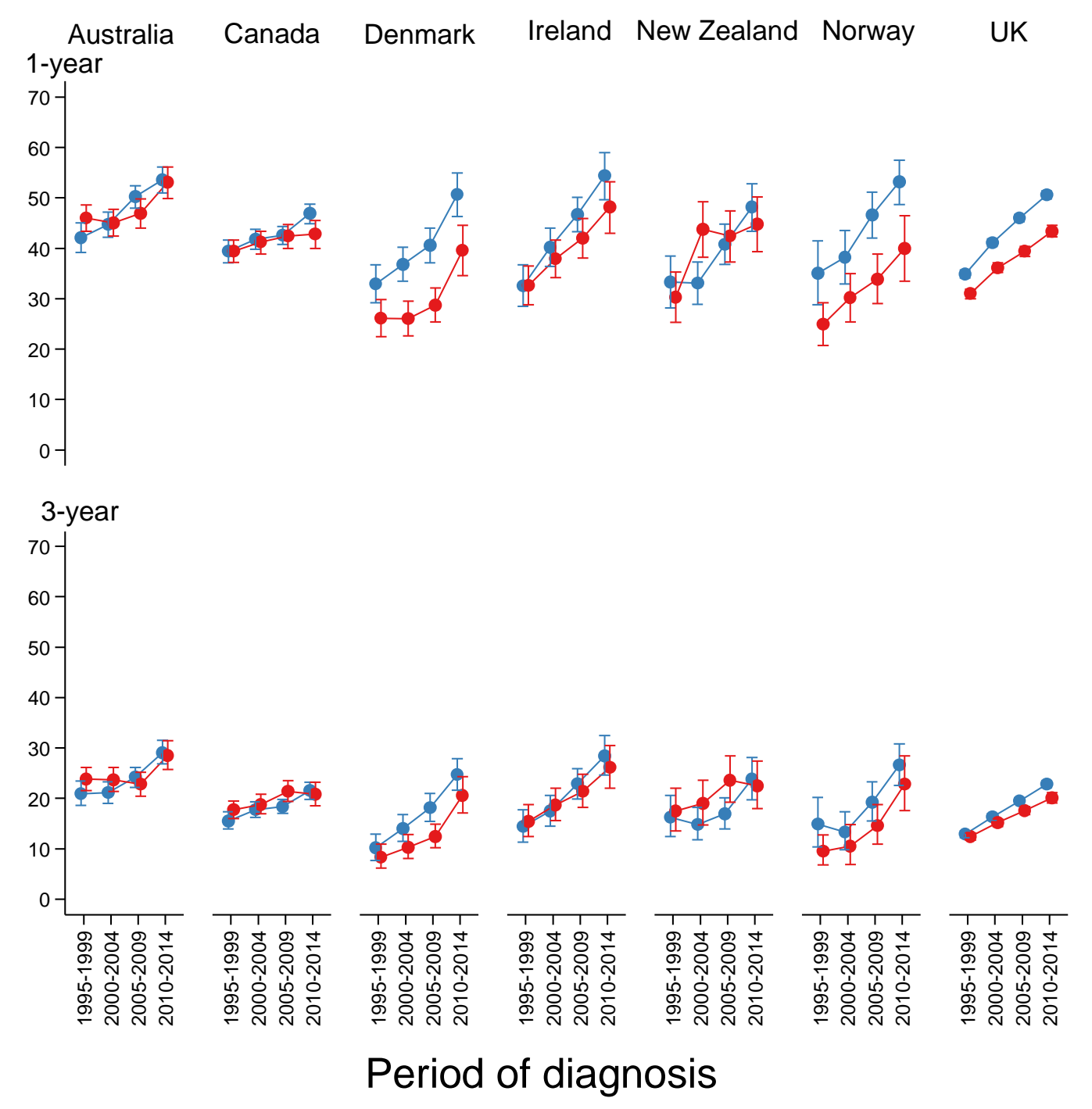

Figure 2: Age-standardized 1- and 3-year net survival estimates and corresponding 95\% confidence limits of oesophageal adenocarcinoma (blue) and squamous cell carcinoma (red) by country and period of diagnosis 


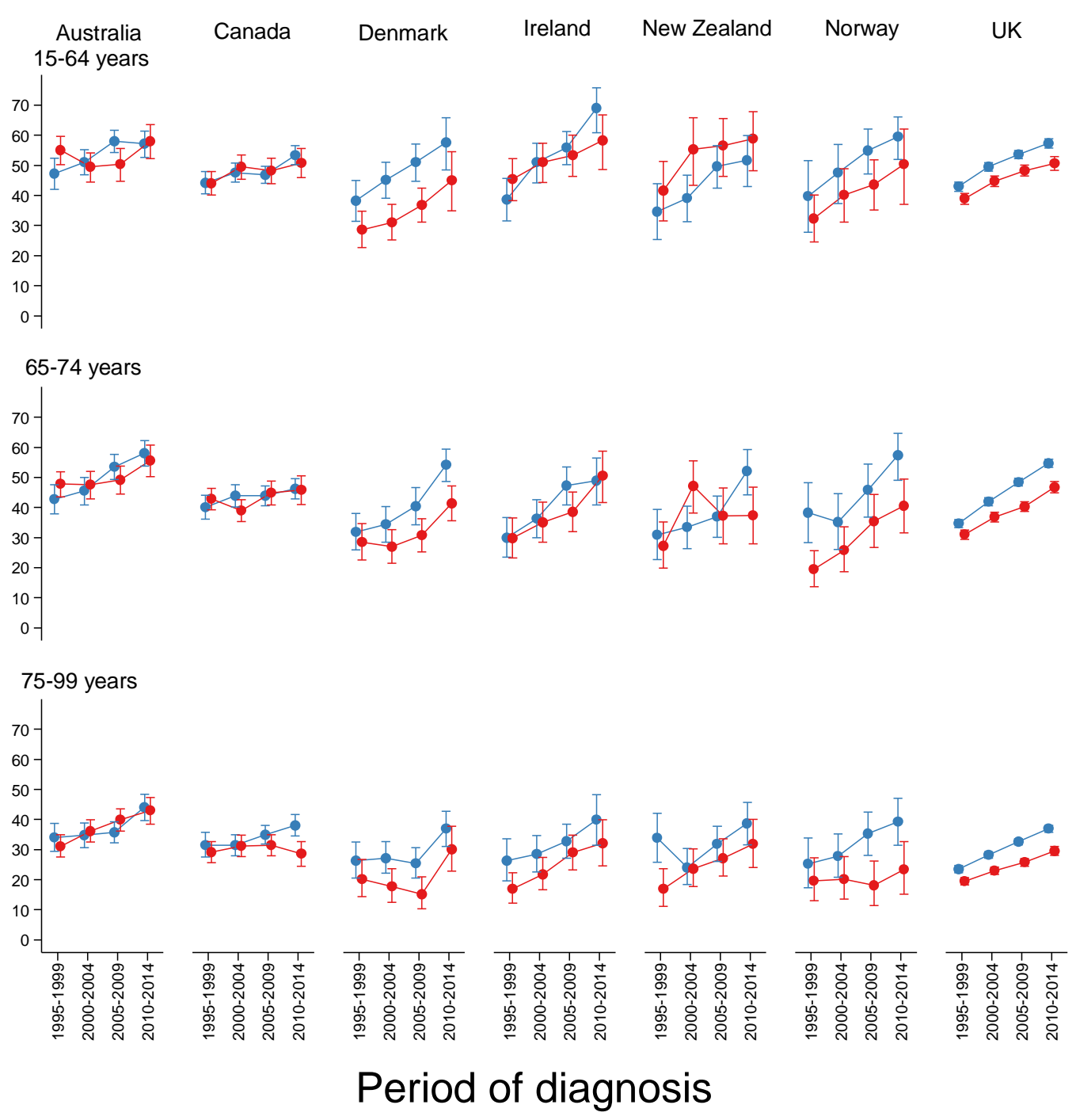

Figure 3a: One-year net survival estimates and corresponding 95\% confidence limits of oesophageal adenocarcinoma (blue) and squamous cell carcinoma (red) by country, age group and period of diagnosis 

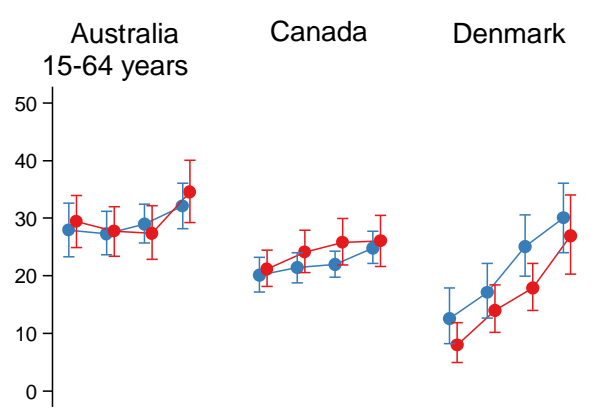

Ireland

New Zealand

Norway

65-74 years
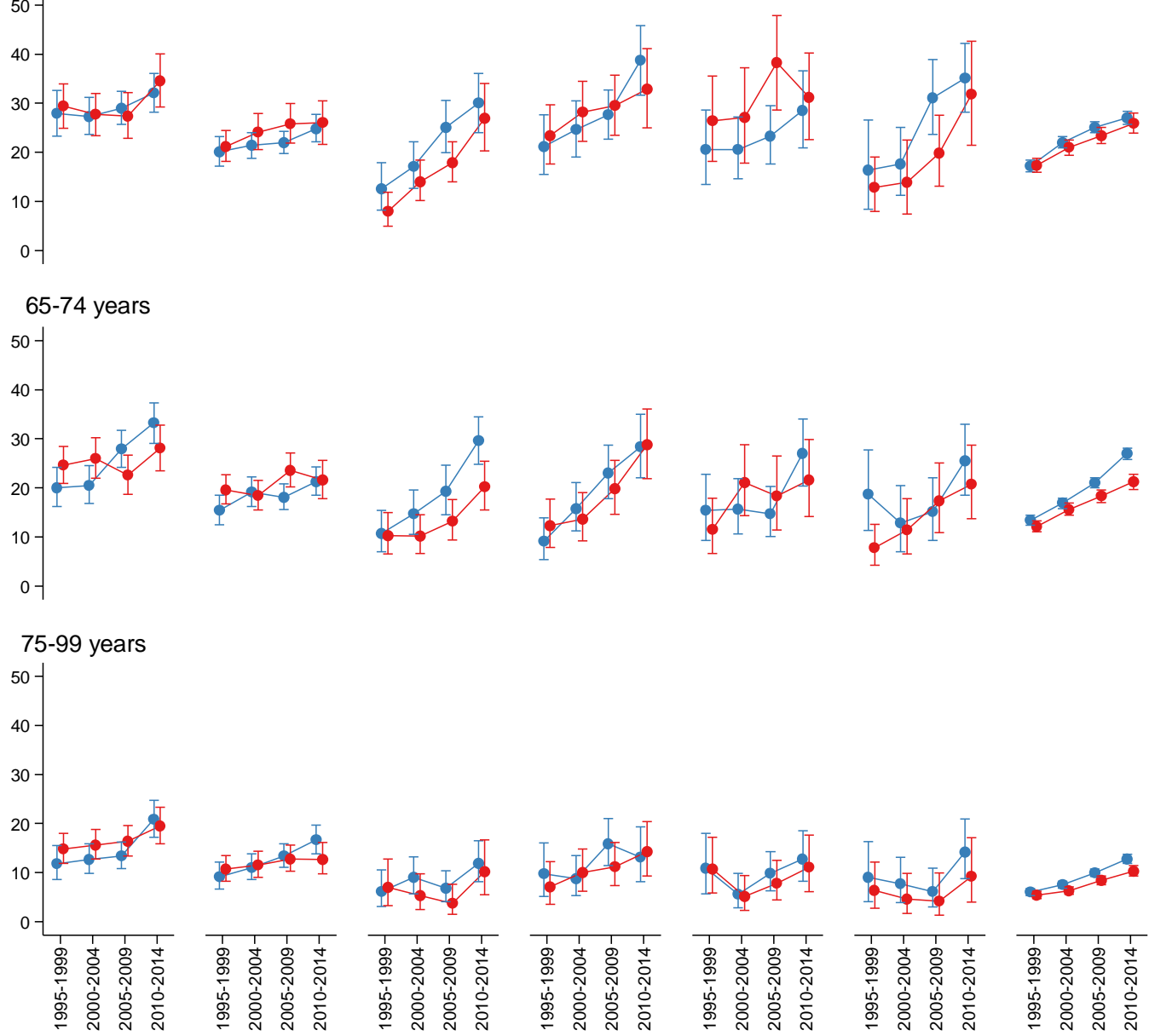

Period of diagnosis

Figure 3b: Three-year net survival estimates and corresponding 95\% confidence limits of oesophageal adenocarcinoma (blue) and squamous cell carcinoma (red) by country, age group and period of diagnosis 


\section{References}

1 Bray F, Ferlay J, Soerjomataram I, et al. Global cancer statistics 2018: GLOBOCAN estimates of incidence and mortality worldwide for 36 cancers in 185 countries. CA Cancer J Clin 2018;68:394-424. doi:10.3322/caac.21492

2 Rustgi AK, El-Serag HB. Esophageal Carcinoma. N Engl J Med 2014;371:2499-509. doi:10.1056/NEJMra1314530

3 El-Serag HB, Hashmi A, Garcia J, et al. Visceral abdominal obesity measured by CT scan is associated with an increased risk of Barrett's oesophagus: a case-control study. Gut 2014;63:220.2-229. doi:10.1136/gutjnl-2012-304189

4 Arnold M, Soerjomataram I, Ferlay J, et al. Global incidence of oesophageal cancer by histological subtype in 2012. Gut 2015;64:381-7. doi:10.1136/gutjnl-2014-308124

5 Shapiro J, van Lanschot JJB, Hulshof MCCM, et al. Neoadjuvant chemoradiotherapy plus surgery versus surgery alone for oesophageal or junctional cancer (CROSS): long-term results of a randomised controlled trial. Lancet Oncol 2015;16:1090-8. doi:10.1016/S14702045(15)00040-6

6 van Hagen P, Hulshof MCCM, van Lanschot JJB, et al. Preoperative Chemoradiotherapy for Esophageal or Junctional Cancer. N Engl J Med 2012;366:2074-84. doi:10.1056/NEJMoa1112088

7 Reece-Smith A, Saunders J, Soomro I, et al. Postoperative survival following perioperative MAGIC versus neoadjuvant OE02-type chemotherapy in oesophageal adenocarcinoma. Ann $R$ Coll Surg Engl 2017;99:378-84. doi:10.1308/rcsann.2017.0024

8 Al-Batran S-E, Homann N, Pauligk C, et al. Perioperative chemotherapy with fluorouracil plus leucovorin, oxaliplatin, and docetaxel versus fluorouracil or capecitabine plus cisplatin and epirubicin for locally advanced, resectable gastric or gastro-oesophageal junction adenocarcinoma (FLOT4): a randomised, phase 2/3 trial. Lancet 2019;393:1948-57. doi:10.1016/S0140-6736(18)32557-1

9 Allum WH, Blazeby JM, Griffin SM, et al. Guidelines for the management of oesophageal and gastric cancer. Gut 2011;60:1449-72. doi:10.1136/GUT.2010.228254

10 Arnold M, Rutherford MJ, Bardot A, et al. Progress in cancer survival, mortality, and incidence in seven high-income countries 1995-2014 (ICBP SURVMARK-2): a population-based study. Lancet Oncol 2019;0. doi:10.1016/S1470-2045(19)30456-5

11 van Putten M, de Vos-Geelen J, Nieuwenhuijzen GAP, et al. Long-term survival improvement in oesophageal cancer in the Netherlands. Eur J Cancer 2018;94:138-47. doi:10.1016/j.ejca.2018.02.025

12 Crane LMA, Schaapveld M, Visser O, et al. Oesophageal cancer in The Netherlands: Increasing incidence and mortality but improving survival. Eur J Cancer 2007;43:1445-51. doi:10.1016/j.ejca.2007.03.024

13 Sundelöf M, Ye W, Dickman PW, et al. Improved survival in both histologic types of oesophageal cancer in Sweden. Int J Cancer 2002;99:751-4. doi:10.1002/ijc.10420

14 van de Poll-Franse L V., Lemmens VEPP, Roukema JA, et al. Impact of concentration of oesophageal and gastric cardia cancer surgery on long-term population-based survival. $\mathrm{Br} J$ 
DRAFT - July 2019

Surg 2011;98:956-63. doi:10.1002/bjs.7493

15 Gavin AT, Francisci S, Foschi R, et al. Oesophageal cancer survival in Europe: A EUROCARE-4 study. Cancer Epidemiol 2012;36:505-12. doi:10.1016/J.CANEP.2012.07.009

16 World Health Organisation. International classification of diseases for oncology. 3rd edn, F. Geneva, Switzerland: 2013.

17 Segi M. Cancer mortality for selected sites in 24 countries. Published Online First: 1969.https://scholar.google.com/scholar_lookup?hl=en\&publication_year=1960\&author=M+ Segi\&title=Cancer+mortality+for+selected+sites+in+24+countries+\%281950-57\%29 (accessed 17 Jan 2019).

18 Perme MP, Stare J, Estève J. On Estimation in Relative Survival. Biometrics 2012;68:113-20. doi:10.1111/j.1541-0420.2011.01640.x

19 Corazziari I, Quinn M, Capocaccia R. Standard cancer patient population for age standardising survival ratios. Eur J Cancer 2004;40:2307-16. doi:10.1016/j.ejca.2004.07.002

20 Brenner $\mathrm{H}$, Gefeller O. An alternative approach to monitoring cancer patient survival. Cancer 1996;78:2004-10.http://www.ncbi.nlm.nih.gov/pubmed/8909323 (accessed 19 Nov 2018).

21 Njei B, McCarty TR, Birk JW. Trends in esophageal cancer survival in United States adults from 1973 to 2009: A SEER database analysis. J Gastroenterol Hepatol 2016;31:1141-6. doi:10.1111/jgh.13289

22 McMenamin ÚC, Kunzmann AT. Do smoking and alcohol behaviours influence Gl cancer survival? Best Pract Res Clin Gastroenterol 2017;31:569-77. doi:10.1016/J.BPG.2017.09.015

23 El-Serag HB, Naik AD, Duan Z, et al. Surveillance endoscopy is associated with improved outcomes of oesophageal adenocarcinoma detected in patients with Barrett's oesophagus. Gut 2016;65:1252-60. doi:10.1136/gutjnl-2014-308865

24 Corley DA, Levin TR, Habel LA, et al. Surveillance and survival in Barrett's adenocarcinomas: a population-based study. Gastroenterology 2002;122:63340.http://www.ncbi.nlm.nih.gov/pubmed/11874995 (accessed 23 Jan 2019).

25 Codipilly DC, Chandar AK, Singh S, et al. The Effect of Endoscopic Surveillance in Patients With Barrett's Esophagus: A Systematic Review and Meta-analysis. Gastroenterology 2018;154:2068-2086.e5. doi:10.1053/j.gastro.2018.02.022

26 Elliott DRF, Walker AW, O'Donovan M, et al. A non-endoscopic device to sample the oesophageal microbiota: a case-control study. Lancet Gastroenterol Hepatol 2017;2:32-42. doi:10.1016/S2468-1253(16)30086-3

27 Murphy G, McCormack V, Abedi-Ardekani B, et al. International cancer seminars: a focus on esophageal squamous cell carcinoma. Ann Oncol 2017;28:2086-93. doi:10.1093/annonc/mdx279

28 World Health Organization. Global Action Plan for the Prevention and Control of Noncommunicable Diseases 2013-2020. 2013. www.who.int (accessed 17 Jan 2019).

29 Jankowski JAZ, de Caestecker J, Love SB, et al. Esomeprazole and aspirin in Barrett's oesophagus (AspECT): a randomised factorial trial. Lancet (London, England) 2018;392:400-8. doi:10.1016/S0140-6736(18)31388-6 
30 Cunningham D, Allum WH, Stenning SP, et al. Perioperative Chemotherapy versus Surgery Alone for Resectable Gastroesophageal Cancer. N Engl J Med 2006;355:11-20. doi:10.1056/NEJMoa055531

31 Medical Research Council Oesophageal Cancer Working Group. Surgical resection with or without preoperative chemotherapy in oesophageal cancer: a randomised controlled trial. Lancet 2002;359:1727-33. doi:10.1016/S0140-6736(02)08651-8

32 Lordick F, Mariette C, Haustermans K, et al. Oesophageal cancer: ESMO Clinical Practice Guidelines for diagnosis, treatment and follow-upt. Ann Oncol 2016;27:v50-7. doi:10.1093/annonc/mdw329

33 Sjoquist KM, Burmeister BH, Smithers BM, et al. Survival after neoadjuvant chemotherapy or chemoradiotherapy for resectable oesophageal carcinoma: an updated meta-analysis. Lancet Oncol 2011;12:681-92. doi:10.1016/S1470-2045(11)70142-5

34 National Board of Health. National Cancer Plan II. 2005. http://www.sst.dk (accessed 25 Jan 2019).

35 Department of Health. The NHS Cancer Plan: a plan for investment, a plan for reform. 2000. https://www.thh.nhs.uk/documents/_Departments/Cancer/NHSCancerPlan.pdf (accessed 25 Jan 2019).

36 Department of Health. Cancer Reform Strategy: Equality Impact Assessment. 2007. https://www.nhs.uk/NHSEngland/NSF/Documents/Cancer Reform Strategy.pdf (accessed 25 Jan 2019).

37 Probst HB, Hussain ZB, Andersen O. Cancer patient pathways in Denmark as a joint effort between bureaucrats, health professionals and politicians-A national Danish project. Health Policy (New York) 2012;105:65-70. doi:10.1016/j.healthpol.2011.11.001

$38 \quad$ National Cancer Forum. A Strategy for Cancer Control in Ireland. 2006. https://www.hse.ie/eng/services/publications/healthprotection/public-health-/nationalcancer-control-strategy.pdf (accessed 3 Jun 2019).

39 Findlay JM, Bradley KM, Maile EJ, et al. Pragmatic staging of oesophageal cancer using decision theory involving selective endoscopic ultrasonography, PET and laparoscopy. $\mathrm{Br} \mathrm{J}$ Surg 2015;102:1488-99. doi:10.1002/bjs.9905

40 Secrier M, Li X, de Silva N, et al. Mutational signatures in esophageal adenocarcinoma define etiologically distinct subgroups with therapeutic relevance. Nat Genet 2016;48:1131-41. doi:10.1038/ng.3659

41 Sarfati D, Koczwara B, Jackson $C$. The impact of comorbidity on cancer and its treatment. $C A$ Cancer J Clin 2016;66:337-50. doi:10.3322/caac.21342

42 Hayes L, Forrest L, Adams J, et al. Age-related inequalities in colon cancer treatment persist over time: a population-based analysis. J Epidemiol Community Health 2018;:jech-2018210842. doi:10.1136/jech-2018-210842

43 Quaglia A, Tavilla A, Shack L, et al. The cancer survival gap between elderly and middle-aged patients in Europe is widening. Eur J Cancer 2009;45:1006-16. doi:10.1016/j.ejca.2008.11.028

44 Wildiers $\mathrm{H}$, Heeren P, Puts M, et al. International Society of Geriatric Oncology Consensus on Geriatric Assessment in Older Patients With Cancer. J Clin Oncol 2014;32:2595-603. 
DRAFT - July 2019

doi:10.1200/JCO.2013.54.8347

45 Mccoll KEL, Going JJ. Aetiology and classification of adenocarcinoma of the gastrooesophageal junction/cardia. doi:10.1136/gut.2009.186825

46 Siewert JR, Stein HJ. Classification of adenocarcinoma of the oesophagogastric junction. $\mathrm{Br} \mathrm{J}$ Surg 1998;85:1457-9. doi:10.1046/j.1365-2168.1998.00940.x 


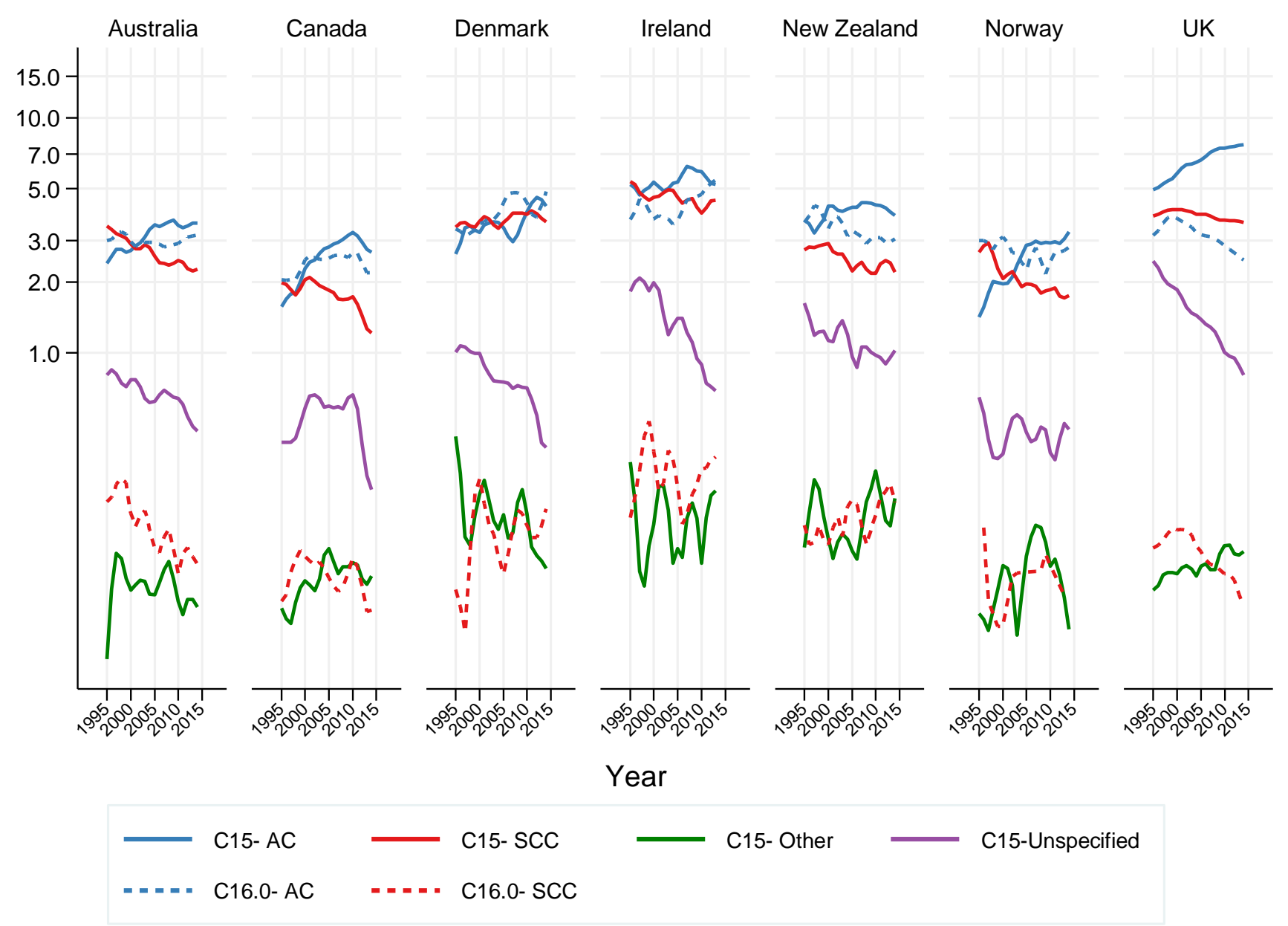

Figure S1: Trends in age-standardised incidence rate per 100,000 of oesophageal (C15) and gastric cardia (C16.0) cancer by histological subtype by country and year of diagnosis, 1995-2014 
Table S1: One- and three-year age-standardised net survival (\%) and corresponding 95\% confidence limits from oesophageal cancer by histological subtype, country and period of diagnosis

\begin{tabular}{|c|c|c|c|c|c|c|c|c|c|}
\hline \multirow[b]{2}{*}{ Country } & \multirow[b]{2}{*}{$\begin{array}{l}\text { Period of } \\
\text { diagnosis }\end{array}$} & \multicolumn{4}{|c|}{ 1-year survival (95\% Cl) } & \multicolumn{4}{|c|}{ 3-year survival (95\% Cl) } \\
\hline & & & $\mathrm{AC}$ & & SCC & & AC & & SCC \\
\hline \multirow{4}{*}{ Australia } & 1995-1999 & 42.1 & $(39.2,45.0)$ & 46.0 & $(43.4,48.6)$ & 20.9 & $(18.6,23.4)$ & 23.8 & $(21.5,26.1)$ \\
\hline & $2000-2004$ & 44.7 & $(42.2,47.2)$ & 45.0 & $(42.4,47.7)$ & 21.1 & $(19.0,23.3)$ & 23.7 & $(21.4,26.1)$ \\
\hline & 2005-2009 & 50.3 & $(48.0,52.4)$ & 46.9 & $(44.0,49.8)$ & 24.2 & $(22.2,26.1)$ & 22.8 & $(20.4,25.2)$ \\
\hline & 2010-2014 & 53.6 & $(51.0,56.1)$ & 53.1 & $(49.9,56.1)$ & 29.1 & $(26.8,31.5)$ & 28.5 & $(25.7,31.4)$ \\
\hline \multirow{4}{*}{ Canada } & 1995-1999 & 39.4 & $(37.1,41.6)$ & 39.4 & $(37.2,41.6)$ & 15.5 & $(13.9,17.3)$ & 17.7 & $(16.0,19.5)$ \\
\hline & $2000-2004$ & 41.8 & $(39.8,43.8)$ & 41.2 & $(38.9,43.4)$ & 17.7 & $(16.2,19.3)$ & 18.8 & $(16.9,20.8)$ \\
\hline & 2005-2009 & 42.6 & $(40.8,44.3)$ & 42.4 & $(40.0,44.7)$ & 18.4 & $(17.0,19.8)$ & 21.4 & $(19.4,23.5)$ \\
\hline & 2010-2014 & 46.9 & $(44.9,48.8)$ & 42.8 & $(40.0,45.5)$ & 21.5 & (19.8,23.2) & 20.8 & $(18.5,23.2)$ \\
\hline \multirow{4}{*}{ Denmark } & 1995-1999 & 32.9 & $(29.2,36.7)$ & 26.1 & $(22.5,29.8)$ & 10.2 & $(7.7,12.9)$ & 8.3 & $(6.2,10.9)$ \\
\hline & 2000-2004 & 36.8 & $(33.5,40.2)$ & 26.0 & $(22.6,29.5)$ & 14.0 & $(11.5,16.8)$ & 10.3 & $(8.1,12.8)$ \\
\hline & 2005-2009 & 40.6 & $(37.1,44.0)$ & 28.7 & $(25.4,32.1)$ & 18.1 & $(15.4,21.0)$ & 12.4 & $(10.2,14.9)$ \\
\hline & 2010-2014 & 50.7 & $(46.3,54.9)$ & 39.6 & $(34.6,44.6)$ & 24.7 & $(21.6,27.9)$ & 20.6 & $(17.1,24.3)$ \\
\hline \multirow{4}{*}{ Ireland } & 1995-1999 & 32.5 & $(28.5,36.7)$ & 32.6 & $(28.8,36.5)$ & 14.4 & $(11.3,17.7)$ & 15.4 & $(12.4,18.8)$ \\
\hline & $2000-2004$ & 40.2 & $(36.4,44.0)$ & 37.9 & $(34.2,41.6)$ & 17.5 & $(14.5,20.6)$ & 18.7 & $(15.6,22.0)$ \\
\hline & 2005-2009 & 46.7 & $(43.3,50.1)$ & 42.0 & $(38.1,45.9)$ & 22.9 & $(19.9,25.9)$ & 21.4 & $(18.2,24.8)$ \\
\hline & 2010-2014 & 54.4 & $(49.6,59.0)$ & 48.2 & $(43.0,53.2)$ & 28.4 & $(24.6,32.5)$ & 26.1 & $(22.0,30.5)$ \\
\hline \multirow{4}{*}{$\begin{array}{l}\text { New } \\
\text { Zealand }\end{array}$} & 1995-1999 & 33.3 & $(28.2,38.5)$ & 30.3 & $(25.3,35.3)$ & 16.2 & $(12.4,20.6)$ & 17.5 & $(13.5,22.0)$ \\
\hline & 2000-2004 & 33.1 & $(28.9,37.3)$ & 43.8 & $(38.2,49.2)$ & 14.8 & $(11.8,18.2)$ & 19.0 & $(14.7,23.6)$ \\
\hline & 2005-2009 & 40.8 & $(36.8,44.8)$ & 42.4 & $(37.3,47.4)$ & 16.9 & $(13.9,20.1)$ & 23.6 & $(19.2,28.4)$ \\
\hline & 2010-2014 & 48.2 & $(43.4,52.8)$ & 44.8 & $(39.3,50.2)$ & 23.8 & $(19.7,28.1)$ & 22.5 & $(18.0,27.4)$ \\
\hline \multirow{4}{*}{ Norway } & 1995-1999 & 35.1 & $(28.8,41.5)$ & 24.9 & $(20.7,29.2)$ & 14.9 & $(10.4,20.2)$ & 9.5 & $(6.8,12.7)$ \\
\hline & 2000-2004 & 38.2 & $(32.9,43.5)$ & 30.2 & $(25.4,35.0)$ & 13.3 & $(9.8,17.3)$ & 10.5 & $(6.9,14.8)$ \\
\hline & 2005-2009 & 46.6 & $(42.0,51.1)$ & 33.9 & $(29.0,38.9)$ & 19.2 & $(15.5,23.3)$ & 14.6 & $(10.9,18.8)$ \\
\hline & 2010-2014 & 53.2 & $(48.7,57.5)$ & 40.0 & $(33.5,46.5)$ & 26.6 & $(22.6,30.8)$ & 22.8 & $(17.6,28.4)$ \\
\hline \multirow{4}{*}{ UK } & 1995-1999 & 34.9 & $(34.1,35.7)$ & 31.0 & $(30.0,31.9)$ & 12.9 & $(12.2,13.5)$ & 12.4 & $(11.7,13.1)$ \\
\hline & 2000-2004 & 41.1 & $(40.4,41.9)$ & 36.1 & $(35.2,37.1)$ & 16.3 & $(15.7,16.9)$ & 15.2 & $(14.4,15.9)$ \\
\hline & 2005-2009 & 46.0 & $(45.3,46.7)$ & 39.4 & $(38.4,40.4)$ & 19.5 & $(18.9,20.1)$ & 17.6 & $(16.8,18.4)$ \\
\hline & 2010-2014 & 50.6 & $(49.8,51.4)$ & 43.4 & $(42.3,44.6)$ & 22.8 & $(22.1,23.5)$ & 20.1 & $(19.1,21.1)$ \\
\hline
\end{tabular}


DRAFT - July 2019

Table S2: Age-standardized one- and three-year net survival (\%) and corresponding 95\% confidence limits from oesophageal cancer by histological subtype, jurisdiction and period of diagnosis

\begin{tabular}{|c|c|c|c|c|c|c|c|c|c|c|}
\hline \multirow{2}{*}{\multicolumn{2}{|c|}{$\begin{array}{c}\text { Country/ } \\
\text { Jurisdiction }\end{array}$}} & \multirow[b]{2}{*}{ Period of diagnosis } & \multicolumn{4}{|c|}{ 1-year survival $(95 \% \mathrm{Cl})$} & \multicolumn{4}{|c|}{ 3-year survival $(95 \% \mathrm{Cl})$} \\
\hline & & & & $A C$ & & $\operatorname{scc}$ & & AC & & SCC \\
\hline \multirow{12}{*}{ Australia } & \multirow{4}{*}{ NSW } & $1995-1999$ & 40.0 & $(35.7,44.3)$ & 47.7 & $(44.1,51.2)$ & 20.0 & $(16.6,23.7)$ & 25.4 & $(22.0,28.9)$ \\
\hline & & $2000-2004$ & 42.9 & $(39.2,46.5)$ & 41.3 & $(37.6,45.0)$ & 21.8 & $(18.7,25.0)$ & 22.1 & $(18.9,25.4)$ \\
\hline & & 2005-2009 & 47.1 & $(43.9,50.2)$ & 44.3 & $(40.3,48.2)$ & 24.0 & $(21.3,26.8)$ & 21.5 & $(18.3,24.8)$ \\
\hline & & $2010-2014$ & 52.3 & $(48.2,56.2)$ & 49.4 & $(45.0,53.6)$ & 27.5 & $(23.7,31.4)$ & 24.5 & $(20.9,28.3)$ \\
\hline & \multirow{4}{*}{ VIC } & 1995-1999 & 44.4 & $(39.7,48.9)$ & 44.5 & $(39.7,49.2)$ & 22.5 & $(18.6,26.6)$ & 21.9 & $(18.0,25.9)$ \\
\hline & & $2000-2004$ & 46.4 & $(42.3,50.4)$ & 51.3 & $(46.7,55.7)$ & 20.0 & $(16.7,23.5)$ & 28.6 & $(24.6,32.7)$ \\
\hline & & $2005-2009$ & 52.4 & $(48.7,56.0)$ & 48.7 & $(43.5,53.7)$ & 24.1 & $(20.9,27.4)$ & 24.5 & $(20.3,29.0)$ \\
\hline & & $2010-2014$ & 54.0 & $(49.8,58.1)$ & 60.5 & $(55.8,64.9)$ & 31.4 & $(27.6,35.3)$ & 40.6 & $(36.3,45.0)$ \\
\hline & \multirow{4}{*}{ WA } & 1995-1999 & 43.8 & $(35.6,51.8)$ & 42.7 & $(35.6,49.6)$ & 20.2 & $(14.1,27.0)$ & 21.9 & $(16.2,28.2)$ \\
\hline & & $2000-2004$ & 46.2 & $(39.8,52.3)$ & 43.0 & $(35.7,50.0)$ & 21.6 & $(16.5,27.2)$ & 17.2 & $(12.0,23.2)$ \\
\hline & & $2005-2009$ & 55.3 & $(49.5,60.8)$ & 51.9 & $(43.3,59.8)$ & 25.1 & $(20.1,30.4)$ & 23.8 & $(17.8,30.2)$ \\
\hline & & $2010-2014$ & 58.2 & $(51.6,64.3)$ & 57.1 & $(48.9,64.5)$ & 30.2 & $(24.5,36.1)$ & 34.8 & $(27.5,42.2)$ \\
\hline \multirow{17}{*}{ Canada } & \multirow{4}{*}{$A B$} & 1995-1999 & 46.2 & $(37.7,54.3)$ & 29.2 & $(21.9,36.8)$ & 20.4 & $(14.1,27.5)$ & 11.0 & $(6.9,16.3)$ \\
\hline & & $2000-2004$ & 37.4 & $(30.6,44.1)$ & 38.0 & $(31.3,44.7)$ & 17.0 & $(12.2,22.4)$ & 19.3 & $(13.9,25.3)$ \\
\hline & & $2005-2009$ & 42.2 & $(37.2,47.1)$ & 33.8 & $(27.6,40.1)$ & 15.2 & $(11.7,19.1)$ & 12.6 & $(8.4,17.6)$ \\
\hline & & $2010-2014$ & 41.5 & $(36.4,46.5)$ & 45.3 & $(37.1,53.1)$ & 19.8 & $(15.9,23.9)$ & 25.9 & $(19.2,33.1)$ \\
\hline & \multirow{4}{*}{$\mathrm{BC}$} & 1995-1999 & 38.2 & $(33.3,43.1)$ & 37.4 & $(32.1,42.7)$ & 13.4 & $(10.1,17.2)$ & 16.5 & $(12.9,20.6)$ \\
\hline & & $2000-2004$ & 39.0 & $(34.6,43.3)$ & 42.1 & $(37.2,46.9)$ & 16.3 & $(13.1,19.8)$ & 18.3 & $(14.2,22.8)$ \\
\hline & & $2005-2009$ & 45.3 & $(41.0,49.4)$ & 42.6 & $(36.5,48.6)$ & 20.9 & $(17.5,24.5)$ & 22.9 & $(18.5,27.5)$ \\
\hline & & $2010-2014$ & 47.6 & $(43.1,52.0)$ & 48.2 & $(42.8,53.4)$ & 21.0 & $(17.0,25.3)$ & 24.3 & $(19.2,29.6)$ \\
\hline & & & & & & & & & & \\
\hline & \multirow{4}{*}{ MB } & 1995-1999 & 35.3 & $(23.1,47.8)$ & 43.8 & $(33.7,53.4)$ & 11.3 & $(4.8,20.9)$ & 12.9 & $(7.1,20.5)$ \\
\hline & & $2000-2004$ & 35.2 & $(25.4,45.1)$ & 34.2 & $(24.2,44.4)$ & 14.6 & $(8.1,23.1)$ & 8.8 & $(3.5,17.0)$ \\
\hline & & $2005-2009$ & 41.2 & $(32.6,49.5)$ & 39.7 & $(27.5,51.6)$ & 16.0 & $(10.1,23.2)$ & 11.0 & $(4.9,19.9)$ \\
\hline & & $2010-2014$ & 44.1 & $(34.9,52.9)$ & 37.9 & $(26.2,49.6)$ & 22.0 & $(13.5,32.0)$ & 10.5 & $(4.3,20.1)$ \\
\hline & \multirow{4}{*}{ NB } & 1995-1999 & 27.8 & $(16.5,40.2)$ & 35.3 & $(24.7,45.9)$ & 7.7 & $(2.4,17.3)$ & 17.6 & $(9.6,27.6)$ \\
\hline & & $2000-2004$ & 38.5 & $(28.4,48.5)$ & 45.2 & $(31.7,57.7)$ & 16.1 & $(9.7,23.9)$ & 15.8 & $(6.9,27.9)$ \\
\hline & & $2005-2009$ & 41.1 & $(32.1,49.8)$ & 39.3 & $(25.7,52.6)$ & 11.8 & $(6.4,18.9)$ & 23.8 & $(13.2,36.2)$ \\
\hline & & $2010-2014$ & 51.7 & $(40.5,61.9)$ & 57.7 & $(39.1,72.4)$ & 16.1 & $(9.1,24.8)$ & 31.7 & $(15.6,49.1)$ \\
\hline
\end{tabular}

AC, Adenocarcinoma; SCC, Squamous cell carcinoma; NSW, New South Wales; VIC, Victoria; WA, Western Australia; AB, Alberta; BC, British Columbia; MB, Mantioba; NB, New Brunswick; NS, Nova Scotia; ON, Ontario; PE, Prince Edward Island; SK, Saskatchewan; ENG, England; NIR, Northern Ireland; SCO, Scotland; WAL, Wales. 
DRAFT - July 2019

Table S2 continued: Age-standardized one- and three-year net survival (\%) and corresponding 95\% confidence limits from oesophageal cancer by histological subtype, jurisdiction and period of diagnosis

\begin{tabular}{|c|c|c|c|c|c|c|c|c|c|}
\hline \multirow{2}{*}{$\begin{array}{c}\text { Country/ } \\
\text { Jurisdiction }\end{array}$} & \multirow[b]{2}{*}{$\begin{array}{l}\text { Period of } \\
\text { diagnosis }\end{array}$} & \multicolumn{4}{|c|}{ 1-year survival $(95 \% \mathrm{Cl})$} & \multicolumn{4}{|c|}{ 3-year survival $(95 \% \mathrm{Cl})$} \\
\hline & & \multicolumn{3}{|c|}{$A C$} & \multirow{2}{*}{$\begin{array}{l}\text { SCC } \\
(27.7,49.4)\end{array}$} & \multicolumn{3}{|c|}{$A C$} & \multirow{2}{*}{$\frac{\text { SCC }}{(7.7,23.7)}$} \\
\hline \multirow{4}{*}{ NS } & 1995-1999 & 35.3 & $(24.9,45.9)$ & 38.6 & & 13.9 & $(7.2,22.7)$ & 14.6 & \\
\hline & $2000-2004$ & 32.7 & $(24.6,41.1)$ & 35.5 & $(24.4,46.8)$ & 14.2 & $(8.7,21.0)$ & 15.4 & $(8.0,25.1)$ \\
\hline & 2005-2009 & 42.9 & $(35.6,50.0)$ & 42.5 & $(29.5,55.0)$ & 15.9 & $(10.4,22.5)$ & 23.0 & $(13.0,34.7)$ \\
\hline & $2010-2014$ & 50.3 & $(42.3,57.8)$ & 23.6 & $(13.1,35.9)$ & 23.4 & $(16.6,30.9)$ & 12.9 & $(5.8,23.0)$ \\
\hline \multirow{4}{*}{ ON } & 1995-1999 & 41.6 & $(38.4,44.7)$ & 42.2 & $(39.0,45.3)$ & 16.9 & $(14.5,19.4)$ & 19.9 & $(17.4,22.6)$ \\
\hline & $2000-2004$ & 46.1 & $(43.3,48.9)$ & 42.9 & $(39.7,46.0)$ & 19.7 & $(17.4,22.0)$ & 20.2 & $(17.6,23.0)$ \\
\hline & 2005-2009 & 42.5 & $(40.0,45.0)$ & 44.7 & $(41.6,47.8)$ & 19.5 & $(17.5,21.5)$ & 24.1 & $(21.1,27.2)$ \\
\hline & $2010-2014$ & 47.7 & $(44.8,50.6)$ & 42.5 & $(38.6,46.3)$ & 22.7 & $(20.1,25.3)$ & 20.7 & $(17.5,24.1)$ \\
\hline \multirow{4}{*}{ PE } & 1995-1999 & 16.6 & $(3.7,37.7)$ & 35.5 & $(11.8,60.5)$ & & & 13.0 & $(1.2,39.1)$ \\
\hline & $2000-2004$ & 38.5 & $(15.7,61.1)$ & 18.1 & $(2.8,44.3)$ & 25.1 & $(8.1,46.8)$ & 18.7 & $(2.8,45.5)$ \\
\hline & $2005-2009$ & 23.5 & $(9.3,41.3)$ & 50.3 & $(19.1,75.2)$ & 18.2 & $(6.3,35.2)$ & 13.5 & $(1.6,38.2)$ \\
\hline & 2010-2014 & 36.1 & $(20.8,51.6)$ & 52.2 & $(16.5,79.1)$ & 23.4 & $(11.7,37.5)$ & 9.9 & $(0.2,42.4)$ \\
\hline \multirow{4}{*}{ SK } & 1995-1999 & 26.0 & $(17.2,35.6)$ & 32.7 & $(23.5,42.2)$ & 13.5 & $(7.1,22.0)$ & 7.4 & $(2.7,15.6)$ \\
\hline & $2000-2004$ & 31.3 & $(22.0,41.1)$ & 31.3 & $(20.7,42.5)$ & 11.2 & $(5.5,19.3)$ & 13.7 & $(7.2,22.3)$ \\
\hline & 2005-2009 & 37.9 & $(28.3,47.3)$ & 32.4 & $(21.6,43.6)$ & 14.7 & $(8.8,22.0)$ & 13.8 & $(6.5,23.7)$ \\
\hline & 2010-2014 & 53.8 & $(43.8,62.8)$ & 29.4 & $(15.9,44.1)$ & 17.0 & $(8.5,28.0)$ & 11.4 & $(4.0,23.1)$ \\
\hline \multirow{4}{*}{ ENG } & 1995-1999 & 34.6 & $(33.6,35.5)$ & 31.2 & $(30.1,32.2)$ & 12.5 & $(11.8,13.2)$ & 12.2 & $(11.4,13.0)$ \\
\hline & 2000-2004 & 41.0 & $(40.1,41.8)$ & 36.5 & $(35.4,37.6)$ & 16.3 & $(15.6,16.9)$ & 15.5 & $(14.7,16.4)$ \\
\hline & 2005-2009 & 45.9 & $(45.1,46.7)$ & 39.9 & $(38.8,40.9)$ & 19.7 & $(19.1,20.4)$ & 18.1 & $(17.2,19.0)$ \\
\hline & $2010-2014$ & 50.7 & $(49.8,51.6)$ & 43.8 & $(42.5,45.1)$ & 23.0 & $(22.3,23.8)$ & 20.6 & $(19.5,21.7)$ \\
\hline \multirow{4}{*}{$\mathrm{NI}$} & 1995-1999 & 42.2 & $(36.7,47.6)$ & 32.4 & $(25.8,39.1)$ & 16.3 & $(12.2,20.9)$ & 13.6 & $(8.9,19.4)$ \\
\hline & $2000-2004$ & 36.7 & $(31.4,42.0)$ & 34.8 & $(28.1,41.5)$ & 15.5 & $(11.5,20.0)$ & 17.1 & $(11.9,23.1)$ \\
\hline & 2005-2009 & 51.0 & $(46.2,55.5)$ & 35.8 & $(29.2,42.4)$ & 26.1 & $(21.9,30.5)$ & 18.2 & $(13.4,23.7)$ \\
\hline & $2010-2014$ & 54.7 & $(49.5,59.5)$ & 43.6 & $(36.1,50.9)$ & 28.2 & $(23.6,33.0)$ & 22.4 & $(15.5,30.2)$ \\
\hline UK & & & & & & & & & \\
\hline \multirow{4}{*}{ SCO } & 1995-1999 & 35.9 & $(33.6,38.3)$ & 29.7 & $(27.2,32.3)$ & 14.1 & $(12.3,16.0)$ & 11.7 & $(10.0,13.6)$ \\
\hline & $2000-2004$ & 42.5 & $(40.1,44.8)$ & 34.5 & $(32.0,37.0)$ & 15.9 & $(14.1,17.8)$ & 13.0 & $(11.0,15.2)$ \\
\hline & 2005-2009 & 45.7 & $(43.3,48.0)$ & 39.0 & $(35.8,42.1)$ & 17.8 & $(16.0,19.7)$ & 16.3 & $(13.8,18.9)$ \\
\hline & $2010-2014$ & 50.1 & $(47.5,52.6)$ & 40.3 & $(37.0,43.5)$ & 21.1 & $(18.8,23.5)$ & 16.7 & $(14.1,19.5)$ \\
\hline \multirow{4}{*}{ WAL } & 1995-1999 & 35.3 & $(31.4,39.1)$ & 30.3 & $(26.3,34.4)$ & 13.1 & $(10.5,15.9)$ & 15.4 & $(12.4,18.8)$ \\
\hline & $2000-2004$ & 42.0 & $(38.8,45.3)$ & 35.9 & $(32.0,39.9)$ & 18.1 & $(15.6,20.8)$ & 14.8 & $(12.0,17.9)$ \\
\hline & 2005-2009 & 45.3 & $(42.1,48.5)$ & 38.0 & $(33.6,42.3)$ & 17.0 & $(14.7,19.5)$ & 15.2 & $(12.1,18.6)$ \\
\hline & $2010-2014$ & 48.9 & $(45.1,52.6)$ & 45.7 & $(40.4,50.9)$ & 20.6 & $(17.5,23.9)$ & 20.9 & $(16.3,25.8)$ \\
\hline
\end{tabular}

AC, Adenocarcinoma; SCC, Squamous cell carcinoma; NSW, New South Wales; VIC, Victoria; WA, Western Australia; AB, Alberta; BC, British Columbia; MB, Mantioba; NB, New Brunswick; NS, Nova Scotia; ON, Ontario; PE, Prince Edward Island; SK, Saskatchewan; ENG, England; NIR, Northern Ireland; SCO, Scotland; WAL, Wales. 
Table S3: Age-standardized one- and three-year net survival and corresponding 95\% confidence limits from oesophageal cancer by histological subtype, sex and period of diagnosis

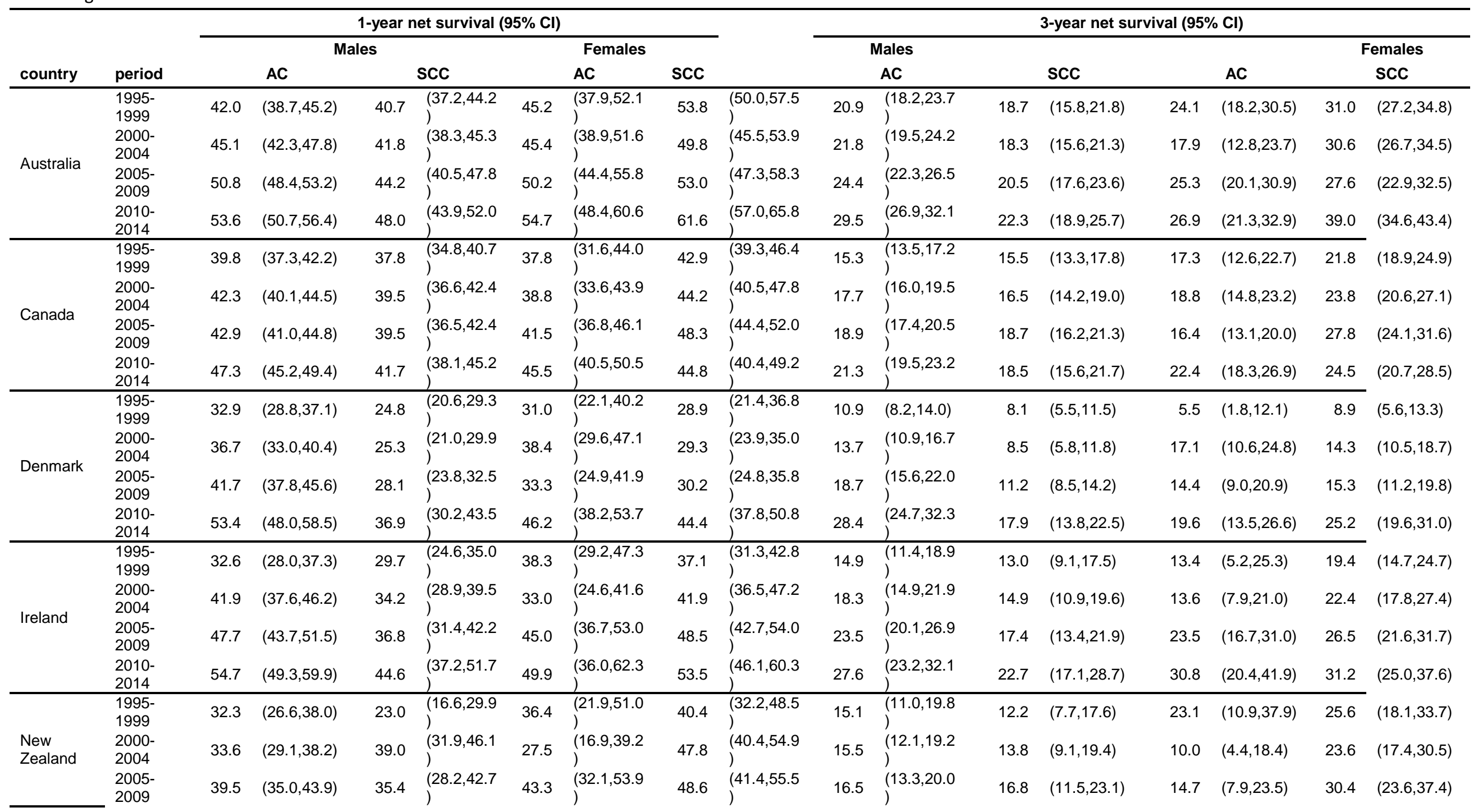


DRAFT - July 2019

\begin{tabular}{|c|c|c|c|c|c|c|c|c|c|c|c|c|c|c|c|c|c|}
\hline & $\begin{array}{l}2010- \\
2014\end{array}$ & 47.5 & $(42.4,52.4)$ & 40.0 & )$^{(32.2,47.7}$ & 52.8 & )$^{(38.8,65.1}$ & 50.4 & )$^{(42.3,58.0}$ & 22.8 & )$^{(18.5,27.5}$ & 20.2 & $(14.0,27.2)$ & 30.2 & $(19.4,41.8)$ & 26.8 & $(20.1,33.9)$ \\
\hline \multirow{4}{*}{ Norway } & $\begin{array}{l}1995- \\
1999\end{array}$ & 35.0 & $(28.2,41.8)$ & 21.8 & )$^{(17.3,26.8}$ & 32.9 & )$^{(17.5,49.1}$ & 30.3 & $l^{(21.9,39.1}$ & 14.6 & $(9.8,20.4)$ & 8.9 & $(6.0,12.6)$ & 18.3 & $(7.6,32.6)$ & 9.6 & $(4.9,16.2)$ \\
\hline & $\begin{array}{l}2000- \\
2004\end{array}$ & 37.8 & $(32.0,43.7)$ & 30.2 & )$^{(24.6,35.9}$ & 39.2 & )$^{(25.1,53.0}$ & 29.2 & (20.3,38.6 & 14.1 & (10.1,18.9 & 10.7 & $(6.4,16.3)$ & 10.3 & $(4.4,19.1)$ & 10.2 & $(5.3,16.9)$ \\
\hline & $\begin{array}{l}2005- \\
2009\end{array}$ & 47.3 & $(42.2,52.2)$ & 31.6 & )$^{(25.5,37.9}$ & 39.5 & )$^{(27.6,51.2}$ & 40.0 & )$^{(31.4,48.4}$ & 18.5 & )$^{(14.5,22.9}$ & 13.0 & $(8.5,18.5)$ & 20.3 & $(11.5,30.8)$ & 19.4 & $(12.9,26.8)$ \\
\hline & $\begin{array}{l}2010- \\
2014 \\
\end{array}$ & 52.2 & $(47.2,56.9)$ & 38.0 & )$^{(30.4,45.6}$ & 59.2 & )$^{(47.5,69.1}$ & 44.9 & )$^{(32.3,56.7}$ & 26.1 & )$^{(21.6,30.8}$ & 21.2 & $(15.1,28.0)$ & 31.8 & $(22.3,41.7)$ & 26.1 & $(16.5,36.6)$ \\
\hline \multirow{4}{*}{ UK } & $\begin{array}{l}1995- \\
1999\end{array}$ & 35.0 & $(34.1,36.0)$ & 27.2 & $l^{(25.9,28.6}$ & 35.6 & )$^{(33.7,37.6}$ & 35.5 & )$^{(34.1,36.8}$ & 12.9 & )$^{(12.2,13.6}$ & 10.2 & $(9.3,11.2)$ & 13.9 & $(12.5,15.5)$ & 15.0 & $(13.9,16.1)$ \\
\hline & $\begin{array}{l}2000- \\
2004\end{array}$ & 41.9 & $(41.0,42.8)$ & 31.2 & )$^{(29.9,32.6}$ & 38.9 & )$^{(37.0,40.7}$ & 41.3 & )$^{(40.0,42.7}$ & 16.4 & )$^{(15.8,17.1}$ & 11.3 & $(10.4,12.3)$ & 16.1 & $(14.7,17.6)$ & 19.4 & $(18.2,20.7)$ \\
\hline & $\begin{array}{l}2005- \\
2009\end{array}$ & 46.4 & $(45.5,47.2)$ & 35.7 & )$^{(34.3,37.1}$ & 45.5 & $(43.8,47.2$ & 43.6 & )$^{(42.3,45.0}$ & 19.6 & (18.9,20.3 & 13.9 & $(12.8,15.0)$ & 20.1 & $(18.6,21.6)$ & 21.8 & $(20.6,23.0)$ \\
\hline & $\begin{array}{l}2010- \\
2014 \\
\end{array}$ & 51.1 & $(50.2,52.0)$ & 39.0 & )$^{(37.4,40.6}$ & 49.8 & )$^{(47.9,51.6}$ & 48.1 & )$^{(46.3,49.8}$ & 22.8 & )$^{(22.0,23.6}$ & 16.4 & $(15.2,17.7)$ & 23.6 & $(22.0,25.2)$ & 24.2 & $(22.6,25.7)$ \\
\hline
\end{tabular}

Table S4: Age-standardized one-year net survival and corresponding 95\% confidence limits from oesophageal cancer by histological subtype, age group and period of diagnosis

\begin{tabular}{|c|c|c|c|c|c|c|c|c|c|c|c|c|c|}
\hline \multirow[b]{2}{*}{ Country } & \multirow{2}{*}{$\begin{array}{l}\text { Period of } \\
\text { diagnosis }\end{array}$} & \multicolumn{4}{|c|}{$15-64$ years } & \multicolumn{4}{|c|}{$65-74$ years } & \multicolumn{4}{|c|}{$75-99$ years } \\
\hline & & & AC & & SCC & & $A C$ & & ScC & & & & SCC \\
\hline \multirow{4}{*}{ Australia } & 1995-1999 & 47.3 & $(42.0,52.4)$ & 55.1 & $(50.2,59.7)$ & 42.7 & $(37.9,47.5)$ & 47.8 & $(43.5,51.9)$ & 34.0 & $(29.4,38.7)$ & 31.1 & $(27.5,34.9)$ \\
\hline & $2000-2004$ & 51.1 & $(46.9,55.2)$ & 49.5 & $(44.5,54.2)$ & 45.5 & $(40.8,50.0)$ & 47.5 & $(42.8,52.0)$ & 34.8 & $(30.7,38.8)$ & 36.2 & $(32.5,39.9)$ \\
\hline & 2005-2009 & 58.0 & $(54.3,61.6)$ & 50.3 & $(44.7,55.6)$ & 53.5 & $(49.3,57.6)$ & 49.2 & $(44.4,53.8)$ & 35.7 & $(32.2,39.2)$ & 39.9 & $(36.1,43.6)$ \\
\hline & $2010-2014$ & 57.2 & $(52.7,61.4)$ & 58.1 & $(52.3,63.5)$ & 58.1 & $(53.8,62.2)$ & 55.6 & $(50.2,60.7)$ & 44.1 & $(39.7,48.4)$ & 43.0 & $(38.5,47.3)$ \\
\hline \multirow{4}{*}{ Canada } & 1995-1999 & 44.2 & $(40.5,47.9)$ & 44.1 & $(40.2,48.0)$ & 40.1 & $(36.1,44.0)$ & 42.8 & $(39.2,46.4)$ & 31.5 & $(27.5,35.7)$ & 29.1 & $(25.6,32.7)$ \\
\hline & $2000-2004$ & 47.6 & $(44.4,50.7)$ & 49.5 & $(45.4,53.5)$ & 43.9 & $(40.2,47.5)$ & 39.0 & $(35.3,42.6)$ & 31.5 & $(28.0,35.0)$ & 31.2 & $(27.7,34.8)$ \\
\hline & $2005-2009$ & 46.9 & $(44.1,49.7)$ & 48.2 & $(43.9,52.4)$ & 43.9 & $(40.6,47.2)$ & 44.9 & $(40.9,48.8)$ & 35.0 & $(31.9,38.1)$ & 31.4 & $(27.9,34.9)$ \\
\hline & $2010-2014$ & 53.4 & $(50.2,56.5)$ & 50.8 & $(45.9,55.6)$ & 46.2 & $(42.8,49.6)$ & 45.8 & $(41.0,50.5)$ & 38.1 & $(34.5,41.6)$ & 28.6 & $(24.5,32.7)$ \\
\hline \multirow{4}{*}{ Denmark } & 1995-1999 & 38.2 & $(31.4,45.0)$ & 28.6 & $(22.6,34.8)$ & 31.8 & $(25.9,38.0)$ & 28.5 & $(22.5,34.7)$ & 26.3 & $(20.5,32.5)$ & 20.2 & $(14.4,26.7)$ \\
\hline & $2000-2004$ & 45.1 & $(39.0,51.0)$ & 31.0 & $(25.2,37.0)$ & 34.4 & $(28.5,40.3)$ & 27.0 & $(21.5,32.7)$ & 27.2 & $(22.1,32.6)$ & 17.7 & $(12.5,23.6)$ \\
\hline & $2005-2009$ & 51.1 & $(44.7,57.1)$ & 36.8 & $(31.1,42.4)$ & 40.5 & $(34.3,46.6)$ & 30.7 & $(25.3,36.2)$ & 25.4 & $(20.5,30.6)$ & 15.2 & $(10.3,21.0)$ \\
\hline & $2010-2014$ & 57.6 & $(48.5,65.8)$ & 45.0 & $(34.9,54.6)$ & 54.2 & $(48.7,59.4)$ & 41.4 & $(35.6,47.1)$ & 36.9 & $(31.1,42.7)$ & 30.1 & $(22.8,37.7)$ \\
\hline \multirow{4}{*}{ Ireland } & 1995-1999 & 38.7 & $(31.6,45.7)$ & 45.4 & $(38.3,52.2)$ & 29.9 & $(23.5,36.6)$ & 29.8 & $(23.2,36.5)$ & 26.4 & $(19.6,33.6)$ & 16.9 & $(12.2,22.3)$ \\
\hline & $2000-2004$ & 51.0 & $(44.2,57.4)$ & 51.0 & $(44.3,57.3)$ & 36.3 & $(29.9,42.6)$ & 35.1 & $(28.5,41.8)$ & 28.5 & $(22.6,34.7)$ & 21.7 & $(16.6,27.4)$ \\
\hline & 2005-2009 & 55.9 & $(50.2,61.2)$ & 53.4 & $(46.3,60.1)$ & 47.3 & $(40.9,53.5)$ & 38.6 & $(31.9,45.1)$ & 32.8 & $(27.2,38.5)$ & 29.0 & $(23.3,34.8)$ \\
\hline & $2010-2014$ & 69.0 & $(60.8,75.8)$ & 58.3 & $(48.6,66.8)$ & 48.9 & $(40.9,56.5)$ & 50.5 & $(41.7,58.7)$ & 39.9 & $(31.5,48.2)$ & 32.1 & $(24.6,39.9)$ \\
\hline
\end{tabular}




\begin{tabular}{|c|c|c|c|c|c|c|c|c|c|c|c|c|c|}
\hline & 1995-1999 & 34.6 & $(25.4,43.9)$ & 41.6 & $(31.6,51.3)$ & 30.9 & $(22.7,39.4)$ & 27.3 & $(19.9,35.2)$ & 33.8 & $(25.8,42.0)$ & 16.9 & $(11.1,23.7)$ \\
\hline New & $2000-2004$ & 39.1 & $(31.3,46.8)$ & 55.3 & $(43.3,65.8)$ & 33.4 & $(26.3,40.5)$ & 47.1 & $(38.1,55.5)$ & 24.1 & $(18.4,30.4)$ & 23.7 & $(17.7,30.3)$ \\
\hline \multirow[t]{2}{*}{ Zealand } & $2005-2009$ & 49.7 & $(42.4,56.6)$ & 56.5 & $(46.3,65.5)$ & 37.0 & $(30.1,43.8)$ & 37.2 & $(27.9,46.5)$ & 31.8 & $(26.0,37.7)$ & 27.2 & $(21.2,33.6)$ \\
\hline & $2010-2014$ & 51.7 & $(42.9,59.9)$ & 58.8 & $(48.2,67.9)$ & 52.1 & $(44.2,59.3)$ & 37.3 & $(27.9,46.7)$ & 38.7 & $(31.6,45.7)$ & 31.9 & $(24.0,40.1)$ \\
\hline \multirow{4}{*}{ Norway } & 1995-1999 & 39.8 & $(27.8,51.6)$ & 32.3 & $(24.6,40.1)$ & 38.3 & $(28.3,48.2)$ & 19.4 & $(13.7,25.7)$ & 25.2 & $(17.3,33.8)$ & 19.6 & $(13.0,27.3)$ \\
\hline & $2000-2004$ & 47.5 & $(37.3,57.0)$ & 40.1 & $(31.1,48.9)$ & 35.2 & $(26.0,44.6)$ & 25.8 & $(18.6,33.6)$ & 27.8 & $(20.8,35.2)$ & 20.1 & $(13.5,27.7)$ \\
\hline & $2005-2009$ & 55.0 & $(47.2,62.1)$ & 43.7 & $(35.2,51.9)$ & 45.8 & $(36.8,54.4)$ & 35.4 & $(26.7,44.3)$ & 35.3 & $(28.1,42.5)$ & 18.2 & $(11.4,26.2)$ \\
\hline & $2010-2014$ & 59.5 & $(52.0,66.1)$ & 50.3 & $(37.0,62.1)$ & 57.4 & $(49.1,64.7)$ & 40.6 & $(31.6,49.4)$ & 39.3 & $(31.5,47.0)$ & 23.4 & $(15.2,32.6)$ \\
\hline \multirow{4}{*}{ UK } & 1995-1999 & 43.0 & $(41.4,44.5)$ & 38.9 & $(37.0,40.7)$ & 34.6 & $(33.3,36.0)$ & 31.0 & $(29.4,32.5)$ & 23.5 & $(22.3,24.7)$ & 19.5 & $(18.3,20.7)$ \\
\hline & $2000-2004$ & 49.5 & $(48.1,50.9)$ & 44.7 & $(42.9,46.5)$ & 41.9 & $(40.6,43.2)$ & 36.8 & $(35.2,38.4)$ & 28.2 & $(27.1,29.3)$ & 23.0 & $(21.8,24.2)$ \\
\hline & 2005-2009 & 53.6 & $(52.3,54.9)$ & 48.2 & $(46.4,50.1)$ & 48.4 & $(47.2,49.7)$ & 40.3 & $(38.7,41.9)$ & 32.6 & $(31.6,33.6)$ & 25.8 & $(24.5,27.0)$ \\
\hline & $2010-2014$ & 57.3 & $(55.8,58.8)$ & 50.7 & $(48.4,52.9)$ & 54.7 & $(53.4,56.0)$ & 46.8 & $(44.9,48.7)$ & 36.9 & $(35.7,38.1)$ & 29.6 & $(28.1,31.1)$ \\
\hline
\end{tabular}

Table S5: Age-standardized three-year net survival and corresponding 95\% confidence limits from oesophageal cancer by histological subtype, age group and period of diagnosis

\begin{tabular}{|c|c|c|c|c|c|c|c|c|c|c|c|c|c|}
\hline \multirow[b]{2}{*}{ Country } & \multirow{2}{*}{$\begin{array}{l}\text { Period of } \\
\text { diagnosis }\end{array}$} & \multicolumn{4}{|c|}{$15-64$ years } & \multicolumn{4}{|c|}{$65-74$ years } & \multicolumn{4}{|c|}{$75-99$ years } \\
\hline & & & $A C$ & & SCC & & $A C$ & & SCC & & $A C$ & & SCC \\
\hline \multirow{4}{*}{ Australia } & 1995-1999 & 27.9 & $(23.3,32.6)$ & 29.4 & $(24.9,33.9)$ & 20.0 & $(16.2,24.2)$ & 24.6 & $(20.9,28.4)$ & 11.8 & $(8.6,15.5)$ & 14.8 & $(11.9,18.0)$ \\
\hline & $2000-2004$ & 27.3 & $(23.6,31.2)$ & 27.7 & $(23.4,32.0)$ & 20.5 & $(16.8,24.5)$ & 26.0 & $(22.0,30.2)$ & 12.7 & $(9.8,15.9)$ & 15.6 & $(12.8,18.8)$ \\
\hline & 2005-2009 & 29.0 & $(25.7,32.4)$ & 27.4 & $(22.8,32.2)$ & 27.9 & $(24.2,31.7)$ & 22.6 & $(18.7,26.7)$ & 13.4 & $(10.8,16.2)$ & 16.4 & $(13.4,19.6)$ \\
\hline & $2010-2014$ & 32.1 & $(28.2,36.1)$ & 34.6 & $(29.2,40.1)$ & 33.2 & $(29.1,37.3)$ & 28.1 & $(23.5,32.8)$ & 20.8 & $(17.2,24.7)$ & 19.5 & $(15.9,23.3)$ \\
\hline \multirow{4}{*}{ Canada } & 1995-1999 & 20.1 & $(17.2,23.2)$ & 21.2 & $(18.1,24.4)$ & 15.4 & $(12.5,18.5)$ & 19.6 & $(16.7,22.7)$ & 9.1 & $(6.6,12.1)$ & 10.7 & $(8.2,13.5)$ \\
\hline & $2000-2004$ & 21.4 & $(18.8,24.0)$ & 24.1 & $(20.5,27.9)$ & 19.1 & $(16.2,22.2)$ & 18.4 & $(15.5,21.5)$ & 11.0 & $(8.6,13.8)$ & 11.5 & $(9.0,14.4)$ \\
\hline & 2005-2009 & 22.0 & $(19.7,24.3)$ & 25.8 & $(21.9,29.9)$ & 18.1 & $(15.6,20.8)$ & 23.6 & $(20.2,27.1)$ & 13.4 & $(11.1,15.9)$ & 12.8 & $(10.3,15.6)$ \\
\hline & $2010-2014$ & 24.8 & $(22.1,27.7)$ & 26.0 & $(21.6,30.5)$ & 21.3 & $(18.5,24.3)$ & 21.6 & $(17.8,25.6)$ & 16.7 & $(13.8,19.7)$ & 12.7 & $(9.7,16.1)$ \\
\hline \multirow{4}{*}{ Denmark } & 1995-1999 & 12.6 & $(8.2,17.9)$ & 7.9 & $(4.9,11.8)$ & 10.7 & $(7.0,15.4)$ & 10.3 & $(6.5,15.0)$ & 6.1 & $(3.1,10.5)$ & 7.0 & $(3.3,12.8)$ \\
\hline & $2000-2004$ & 17.1 & $(12.6,22.1)$ & 14.0 & $(10.2,18.4)$ & 14.7 & $(10.5,19.6)$ & 10.2 & $(6.6,14.5)$ & 9.0 & $(5.7,13.2)$ & 5.3 & $(2.5,9.7)$ \\
\hline & 2005-2009 & 25.1 & $(19.9,30.6)$ & 17.9 & $(14.0,22.1)$ & 19.3 & $(14.5,24.6)$ & 13.2 & $(9.4,17.6)$ & 6.8 & $(4.1,10.4)$ & 3.7 & $(1.5,7.6)$ \\
\hline & $2010-2014$ & 30.0 & $(24.0,36.1)$ & 26.9 & $(20.3,34.0)$ & 29.6 & $(24.8,34.5)$ & 20.2 & $(15.5,25.4)$ & 11.9 & $(8.1,16.5)$ & 10.2 & $(5.5,16.7)$ \\
\hline \multirow{5}{*}{ Ireland } & 1995-1999 & 21.2 & $(15.5,27.6)$ & 23.4 & $(17.6,29.7)$ & 9.1 & $(5.4,13.9)$ & 12.3 & $(7.9,17.7)$ & 9.7 & $(5.1,16.0)$ & 7.1 & $(3.5,12.2)$ \\
\hline & $2000-2004$ & 24.6 & $(19.0,30.5)$ & 28.2 & $(22.2,34.5)$ & 15.8 & $(11.2,21.1)$ & 13.6 & $(9.2,19.0)$ & 8.8 & $(5.3,13.5)$ & 10.0 & $(6.2,14.8)$ \\
\hline & 2005-2009 & 27.6 & $(22.7,32.7)$ & 29.5 & $(23.5,35.7)$ & 23.0 & $(17.8,28.7)$ & 19.8 & $(14.6,25.6)$ & 15.9 & $(11.4,21.0)$ & 11.2 & $(7.3,16.1)$ \\
\hline & $2010-2014$ & 38.7 & $(31.6,45.8)$ & 32.9 & $(25.0,41.1)$ & 28.4 & $(22.1,35.0)$ & 28.8 & $(21.9,36.1)$ & 13.1 & $(8.1,19.3)$ & 14.3 & $(9.3,20.4)$ \\
\hline & 1995-1999 & 20.5 & $(13.4,28.6)$ & 26.4 & $(18.1,35.5)$ & 15.4 & $(9.3,22.8)$ & 11.5 & $(6.6,17.9)$ & 10.9 & $(5.7,18.0)$ & 10.7 & $(5.8,17.2)$ \\
\hline
\end{tabular}




\begin{tabular}{|c|c|c|c|c|c|c|c|c|c|c|c|c|c|}
\hline \multirow{3}{*}{$\begin{array}{l}\text { New } \\
\text { Zealand }\end{array}$} & $2000-2004$ & 20.5 & $(14.6,27.2)$ & 27.1 & $(17.8,37.2)$ & 15.7 & $(10.6,21.9)$ & 21.1 & $(14.3,28.8)$ & 5.6 & $(2.8,9.8)$ & 5.1 & $(2.3,9.4)$ \\
\hline & 2005-2009 & 23.3 & $(17.6,29.5)$ & 38.3 & $(28.6,47.9)$ & 14.7 & $(10.1,20.3)$ & 18.3 & $(11.4,26.5)$ & 9.8 & $(6.3,14.3)$ & 7.8 & $(4.4,12.5)$ \\
\hline & 2010-2014 & 28.5 & $(20.9,36.6)$ & 31.2 & $(22.6,40.2)$ & 27.0 & $(20.4,34.0)$ & 21.6 & $(14.2,29.9)$ & 12.8 & $(8.2,18.5)$ & 11.1 & $(6.1,17.6)$ \\
\hline \multirow{4}{*}{ Norway } & 1995-1999 & 16.4 & $(8.4,26.6)$ & 12.8 & $(7.9,19.0)$ & 18.7 & $(11.3,27.7)$ & 7.8 & $(4.2,12.6)$ & 9.0 & $(4.1,16.3)$ & 6.4 & $(2.7,12.1)$ \\
\hline & $2000-2004$ & 17.6 & $(11.2,25.1)$ & 13.9 & $(7.4,22.5)$ & 12.8 & $(7.0,20.5)$ & 11.4 & $(6.5,17.8)$ & 7.7 & $(3.9,13.1)$ & 4.6 & $(1.7,9.8)$ \\
\hline & 2005-2009 & 31.1 & $(23.6,38.9)$ & 19.8 & $(13.1,27.5)$ & 15.1 & $(9.3,22.1)$ & 17.4 & $(10.9,25.1)$ & 6.1 & $(3.0,10.9)$ & 4.2 & $(1.3,9.9)$ \\
\hline & 2010-2014 & 35.1 & $(28.2,42.2)$ & 31.8 & $(21.4,42.6)$ & 25.5 & $(18.5,33.0)$ & 20.7 & $(13.7,28.7)$ & 14.2 & $(8.8,20.9)$ & 9.2 & $(4.0,17.1)$ \\
\hline \multirow{4}{*}{ UK } & 1995-1999 & 17.2 & $(16.0,18.4)$ & 17.3 & $(15.9,18.8)$ & 13.4 & $(12.4,14.4)$ & 12.1 & $(11.1,13.3)$ & 6.0 & $(5.3,6.7)$ & 5.4 & $(4.7,6.2)$ \\
\hline & $2000-2004$ & 22.0 & $(20.9,23.2)$ & 21.0 & $(19.4,22.5)$ & 16.9 & $(15.8,17.9)$ & 15.6 & $(14.4,16.9)$ & 7.5 & $(6.8,8.2)$ & 6.3 & $(5.6,7.1)$ \\
\hline & 2005-2009 & 25.1 & $(24.0,26.2)$ & 23.4 & $(21.8,25.1)$ & 21.0 & $(20.0,22.1)$ & 18.3 & $(17.0,19.6)$ & 9.9 & $(9.2,10.7)$ & 8.4 & $(7.5,9.3)$ \\
\hline & $2010-2014$ & 27.0 & $(25.7,28.3)$ & 25.9 & $(23.9,28.0)$ & 27.0 & $(25.8,28.1)$ & 21.3 & $(19.7,22.8)$ & 12.8 & $(11.9,13.7)$ & 10.3 & $(9.3,11.4)$ \\
\hline
\end{tabular}


DRAFT - July 2019

Figure S2: Age-standardized 1- year net survival estimates and corresponding 95\% confidence limits of oesophageal adenocarcinoma (AC) and the combination of oesophageal AC and gastric cardia (C16.0) cancer by country for patients diagnosed 2010-2014

Abbreviations: AUS=Australia, CAN=Canada, DEN=Denmark, IRE=Ireland, NZ=New Zealand, NOR=Norway, UK=United Kingdom

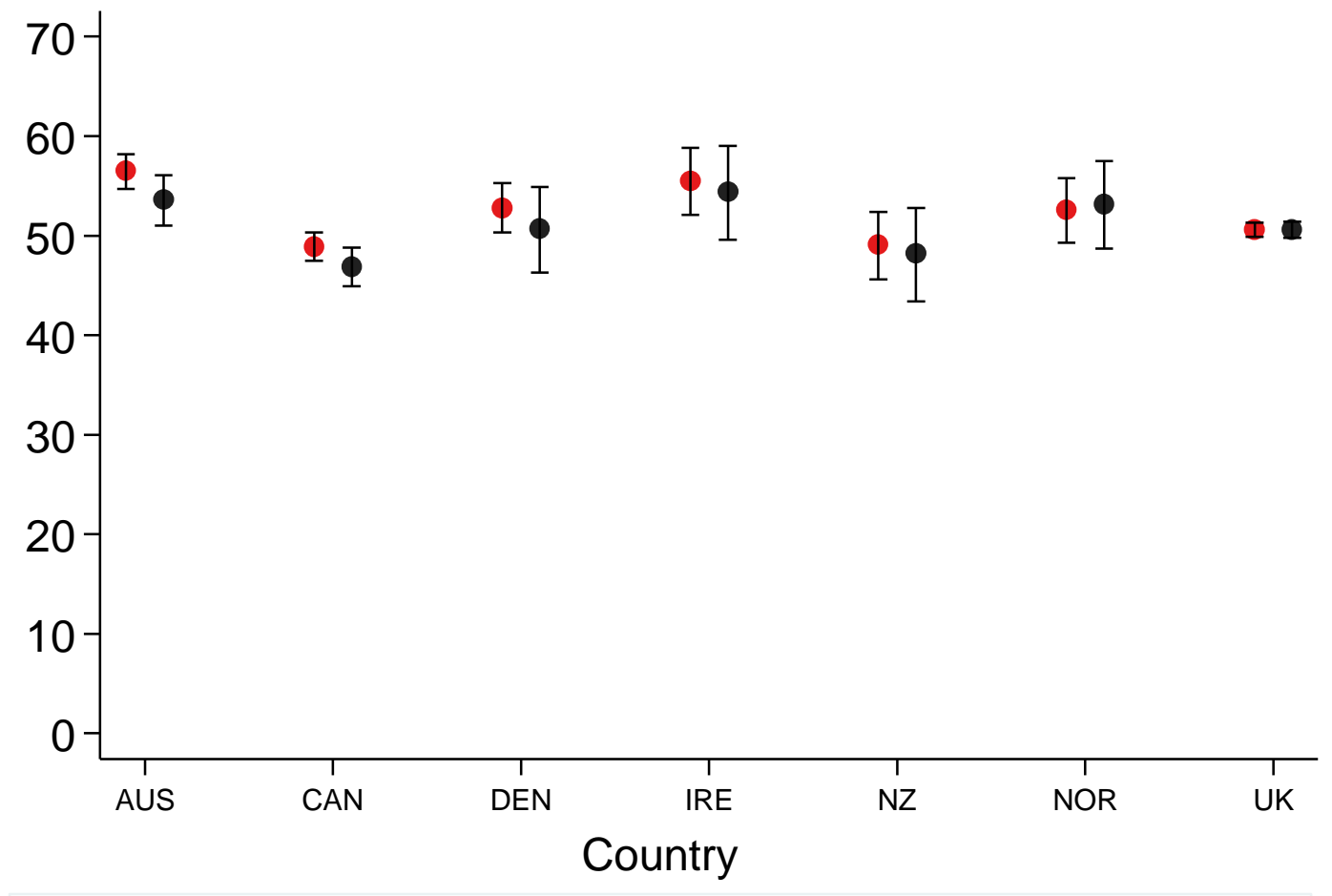

- Oesophageal AC

- Oesophageal AC and gastric cardia 